\title{
Los estatutos de la Universidad de Salamanca, como norma subsidiaria para la de Oviedo, en un pleito académico del siglo XVIII"
}

\author{
Justo García Sánchez
}

Recibido: 28 de enero 2015 • Aprobado: 28 febrero 2015

\section{Resumen}

El objeto de estas páginas consiste en dar a conocer un pleito instado ante el Consejo de Castilla, por el opositor a la cátedra de prima de Leyes de la Universidad de Oviedo, Dr. Benito Antonio García Ruisuárez, contra el entonces rector del Estudio ovetense ${ }^{1}$, a propósito del sistema aplicable a la selección del candidato que aspiraba a cubrir la cátedra de prima de Leyes, vacante en el Estudio universitario (AHN. Sección Consejos. Legajo 35238, exp. 9. Escribania de Cámara: Ayala)².

Palabras clave: universidad, estatutos, juristas, cátedra universitaria.

* Producto de las investigaciones del autor.

* Jurista e historiador; catedrático de Derecho Romano de la Universidad de Oviedo, España. Correo electrónico: jgarcias@uniovi.es

1 El canónigo penitenciario D. Pedro Gómez de la Torre, que también había desempeñado el cargo rectoral durante el año precedente. Era natural de Riaño (León), donde fue bautizado el 11 de agosto de 1689. Bachiller en Teología por la Universidad de Santiago de Compostela, se graduó como licenciado por Salamanca en 1710, obteniendo posteriormente el canonicato lectoral de Tuy, la prebenda magistral de la catedral salmantina, a la que siguió su homónima en Toledo y, finalmente, la penitenciaría de Oviedo, desde donde fue promovido a obispo de Ciudad Rodrigo, sede episcopal que rigió entre 1748 y 1756. Trasladado a la diócesis placentina, fue inhumado en su catedral el 4 de agosto de 1759. Cf. CANELLA SECADES, F., Historia de la Universidad de Oviedo y noticias de los establecimientos de enseñanza de su distrito (Asturias y León), $2^{\mathrm{a}}$ ed., Oviedo 1903-1904, reimpr. 1985, p. 678; AA. VV., Episcopologio Civitatense. Historia de los obispos de Ciudad Rodrigo (1168-2009), Salamanca, CEM, 2010, pp. 323-326.

2 “Obiedo. Año de 1728. El Dr. D. Benito Antonio Garzia Rui Suarez opositor a cathedras de la Universidad de Obiedo, sobre que el Rector guarde y cumpla en todo y por todo los Estatutos de la Universidad de Salamanca y otras cosas. Relator: Lizenciado Salazar. Secretario: Lasalde". AHN. Sección Consejos. Legajo 35238, exp. 9. Escribania de Cámara: Ayala. 


\title{
The By-laws of the University of Salamanca, as a subsidiary rule for Oviedo, in an academic dispute of the eighteenth century
}

\begin{abstract}
The purpose of this pages is to make known a lawsuit filed before the Council of Castilla, by the candidate to the chair of Laws of the University of Oviedo, Dr. Benito Antonio García Ruisuárez against the then chancellor of the Oviedo Studies ${ }^{3}$, with regards to the system applicable to the selection of the candidate aspiring for the chair of Laws, that was vacant in the university Studies. (AHN. Section Councils. File 35238, exp. 9. Chamber Log Scribe: Ayala $)^{4}$.
\end{abstract}

Keywords: University, by-laws, jurists, university chair.

\section{Les Statuts de l'Université de Salamanque, en tant que norme subsidiaire pour celle de Oviedo, dans un litige académique du siècle XVIII}

\section{Résumé}

L'objet de ces pages est de faire connaître un litige engagé devant le Conseil de Castille , par l'opposant à la première chaire de Droit de l'Université de Oviedo, Mr. Benito Antonio

3 The penitentiary priest D. Pedro Gómez de la Torre, who had also held the position of chancellor during preceding year. He was from Riaño (León), where he was baptized on August 11, 1689. Graduate of Theology from University of Santiago de Compostela, licentiate by Salamanca in 1710, obtaining afterwards the canonry at Tuy, the magisterial privilege of the Salamanca chair, to which followed the same one at Toledo and, finally, the penitentiary at Oviedo, from where he was promoted to bishop of Ciudad Rodrigo, episcopal see he ruled between 1748 and 1756. Transferred to the Diocese of Plasencia, he was buried in his cathedral on August 4, 1759. Cf. CANELLA SECADES, F., History of the University of Oviedo and news of the educational institutions of its district (Asturias and Leon), $2^{\text {nd }}$ ed. Oviedo 1903-1904, reprin. 1985, p. 678; AA. VV., Episcopalian Civitatense. History of the bishops of Ciudad Rodrigo (1168-2009), Salamanca, CEM, 2010, pp. 323-326.

4 "Obiedo. Year of 1728. Dr. D. Benito Antonio Garzia Rui Suarez candidate to chairs in the University of Obiedo, on the Chancellor saves and complies in all and by all the By-laws of the University of Salamanca and other things. Commentator Licentiate Salazar. Secretary: Lasalde". Section Councils. File 35238, exp. 9. Chamber Log Scribe: Ayala. 
Garcia Ruisuárez, contre l'ancien Doyen de l'Etude de Oviedo 1, au sujet su système applicable à la sélection du candidat, qui espérait obtenir la première chaire de Droit, poste vacant à l'Etude Universitaire ( AHN), Section Conseils. Dossier 35238, exp.9 Greffe: Ayala). 2

Mots-clés: Université, statuts, juristes, chaire universitaire.

Yo Phelipe Antonio Suarez de la Vega vezino de esta Ziudad de Oviedo notario apostólico y secretario de la Ynsigne Universidad Estudio General y Claustro de ella, Zertifico, doy fee y testimonio de verdad, a todas las Justizias de S. M. (Dios le guarde) y mas que el presente vieren, en como por los Estatutos de esta Universidad se previene y manda, que en los casos omisos y dudosos que se ofrezcan en ella, y no este dispuesto por los de estta dicha Universidad, se observen y guarden los de la Universidad de Salamanca como se executta, en lo que se ofrece, y en ellos, entre otras ay las clausulas siguientes:

En el titulo veinte y uno paragrapho nueve, en la Visita que se hizo por el Sr. Cobarrubias ${ }^{5}$, el año de mil quinientos y sesenta y uno; se ordena que en cada Facultad se prefieran los de aquella Facultad aunque sean menos antiguos y menores en grados que los de otra Facultad. Por manera que los Canonistas se prefieran a los Lexistas y Theologos en sus Generales y lo mismo se guarde en las otras Facultades. Esto no se entiende concurriendo Bachiller con Doctor, porque queremos se prefiera el Doctor al Bachiller, y en titulo treinta y tres paragrapho veinte y seis de la misma visita, se previene, que en las lecciones de obposizion y extraordinarias/ si concurrieren el de mayor grado con el de menor grado siempre se prefiera el de mayor grado, habiendo respeto a la Facultad de que es la Leczion, las quales concuerdan con las que se hallan en dichos Esttattuttos según de ellos consta, a que me refiero y en fee de ello y de pedimento del Doctor D. Benitto Anttonio Garzia Ruysuarez doy el presente que signo y firmo como acostumbro en Oviedo y Mayo veinte de mil settezientos y veinte y ocho = En ttestimonio de verdad: Phelipe Anttonio Suarez de la Vega secretario. Signado y rubricado. (Ibid., fol. s. n. (1) rv.)

5 Así figuraba en la reforma estatutaria que presentó el eminente jurista salmantino, redactada con ocasión de la visita institucional que le confió el Consejo de Castilla. 
Sentado este principio general imperante en la Universidad de Oviedo, por lo que afectaba a dos asuntos de interés académico sobre precedencias y preferencias, el mismo escribano, secretario del Estudio, extiende otra certificación, relativa al conflicto legal que se suscitó en esas materias (Ibid., fols. s. n. (2 y 3) rv.):

Yo Phelipe Antonio Suarez de la Vega vezino de esta Ziudad de Oviedo Notario Apostolico y Secretario de la Ynsigne Universidad Estudio General y Claustro de ella, Zerttifico, Doy fee y testimonio de verdad, a todas las Justizias de S. M. que Dios guarde y mas que el presente vieren, en como habiendo vacado la Catthedra de Prima de Leyes de esta Universidad por Juvilazion del Dr. D. Manuel de Paz su propietario ${ }^{6}$, la que se hizo de orden de los señores del Real y Supremo Consejo de Castilla, en cumplimiento de ella, se mandaron poner edicttos, en la forma ordinaria, lo que se executo, y dentro del termino de ellos se opusieron a dicha Catthedra diferentes obpositores y entre ellos el Dr. D. Benitto Anttonio Garzia Ruysuarez, quien como la mayor parte se junttaron como es costumbre, en la Casa de Morada del Recttor de esta dicha Universidad en virtud de zedula convocatoria, librada, por la que se prebenia, que cada uno llevase sus títulos de Grados para por ellos regularlos y preferirlos según las antigüedades/ y estando en dicho autto, ninguno de dichos obposittores presentto titulo, por cuya razon el dicho Dr. D. Benitto Garzia presentto petizion ante dicho Rector pidiendo que se graduase y regulase las anttiguedades por los Grados que cada uno tuviese en la Facultad de Leyes, y estos prefiriesen a los de Canones, y concurriendo tan solamente entre si los Docttores Graduados en canones, se hubiese de regular la anttiguedad por el Grado que tuviese en leyes aunque fuese menor por no hazer obpositor el Grado de Canones a la Facultad de Leyes y asi se hallaba prevenido por los Estatutos de Salamanca, mandados guardar en esta por los señores del Real y Supremo Consejo de Castilla de lo contrario apelo y protesto el rEal auxilio de la fuerza de que dio traslado a los que se hallaron preenttes; y sin embargo de ello paso dicho Rector a querer regular sin dichos títulos, porque volvió a pedir lo suspendiese ynterin se presentaban y para ello

6 Era hijo de Tomás Serrano de Paz, fallecido en 1693, quien había desempeñado varias cátedras en la Universidad ovetense, desde la de Instituta a la de Prima de Cánones, que fue su última tarea docente. Vid. García Sánchez, J., El Doctor Tomás Serrano de paz (abogado y catedrático ovetense del siglo XVII), Oviedo, RIDEA, 2012; id., Querella contra el Dr. Tomás Serrano de Paz (Por el fiscal del obispo Caballero de Paredes CON el letrado del cabildo). Año 1656, Oviedo, RIDEA, 2014. 
se acompañase con persona que no fuese ninguno de los opositores, ni el Dr. D. Juan Francisco de Paz por ser tio de dos de ellos, y sin embargo de todo paso a hazerse dicha regulazion por dicho Rector con parezer del dicho Dr. Paz aunque no firmo dicho decretto// y para ella se mando saliesen todos los interesados como lo executtaron y por el dicho Rector se dio traslado verbalmente a dichos opositores y en el mismo acto sin otra cosa paso a regular al Dr. D. Zipriano de Villaberde y D. Gabriel de la Villa como graduados en la Facultad de Leyes primero que al Dr. D. Juan de Solares graduado en Canones aunque mas anttiguo y entre los mas Doctores de la Facultad de Canones mando regularlos por la anttiguedad del Grado en esta Facultad sin reconocerse por no haver presentado los títulos a quien podía tocar la antigüedad, en cuya vista por dicho Dr. D. Benitto Garzia se volvió a presentar petizion haciendo relación de que por los Estatutos de Salamanca, en el titulo treinta y tres paragrapho veinte y seis ${ }^{7}$ se prebenia se habían de preferir para leer los Graduados mas antiguos de la Facultad aunque lo fuesen menos que los de otra; y concurriendo Graduados de Canones se havia de atender al Grado de Leyes aunque fuese menor; en cuya virtud se havia pasado a regular primero a los Doctores D. Zipriano y D. Gabriel como graduados en leyes al Dr. D. Juan de Solares aunque mas antiguo de Dr. en Canones, y debiendo en la misma manera regular a los Docttores de Canones por la anttiguedad que tuviesen en la Facultad de Leyes aunque menores en el Grado de Bachiller/ por militar la misma razon, parezia se havia dado prelazion en su compettenzia hallándose Graduado de Dr. en Canones y mas antiguo, en el Grado menor de Leyes, a los doctores D. Joseph y D. Francisco de Granda y D. Fernando de Quiros Docttores en Canones y menos antiguos en el Grado de Leyes,

7 Dicho precepto proviene del antiguo obispo Civitatense, conocido como el Bártolo español, Dr. Diego de Covarrubias y Leyva. En dicho texto se dispone: "Item estatuimos que en las lecciones de oposición y estraordinarias, si concurrieren el de mayor grado con el de menor grado, siempre se prefiera el de mayor grado, aviendo respeto a la Facultad de que es la lecion, y esto se entienda concurriendo los graduados, ò encorporados en esta Universidad, aviendo respeto al dia que se encorporo: y si concurrieren los graduados en otra Universidad, con el graduado en esta, siendo los desta Licenciados se prefieran a los de otra Universidad aunque sean Doctores; pero si fueren Bachilleres desta Universidad, y concurrieren con Dotor, o maestro, ó Licenciado de otra, le sea preferido el Dotor, o Maestro o Licenciado de otra, y si concurrieren graduados de otra, entre si se guarden sus antigüedades y grados". Cf. Estatutos hechos por la Universidad de Salamanca. Recopilados nuevamente. Año de 1625. Impressos en Salamanca por Diego Cusio. Año de 1625, pp. 235-236; ESPERABÉ DE ARTEAGA, E., Historia pragmática e interna de la Universidad de Salamanca. Tomo primero. La Universidad de Salamanca y los Reyes, Salamanca 1914, p. 292.. 
concluyendo em pedir reforma de dicha regulazion mandando guardar las anttiguedades en Leyes, o se suspendiese yntterin lo mandaban los señores del Real Consexo de que apelo y se mando dar traslado por dicho Rector a los interesados que se hallaban presentes que lo entendieron denegandose la apelazion al efecto suspensivo y se le otorgo al deboluttibo:

Y resulta de los libros de Grados haver rezivido, el dicho Dr. D. Benito Garzia, los grados menores y mayores, el de Leyes el año de diez, y en Canones el año de diez y ocho, y de lizenciado y doctor en el año pasado de settezientos y veinte y tres, y exzede en el Grado de Bachiller en Leyes casi quatro años a los Doctores D. Joseph y D. Francisco de Granda y a los Doctores D. Fernando y D. Joseph de Quiros, todo lo qual resulta mejor de la vacantte de dicha Catthedra libros de Grados y mas papeles que en mi ofizio quedan como tal secretario, a que me refiero, y en fee de ello y de pedimiento y requerimiento del dicho Dr. D. Benitto doy el presente que signo y firmo en Oviedo y Mayo veinte de settezientos y veinte y ocho = En testimonio de verdad: Phelipe Anttonio Suarze de la vega, secretario. Signado y rubricado.

Para que prosperara su reclamación contra la elección hecha por el Rector de Oviedo a la hora de asignar las exposiciones de los distintos opositores, Benito Antonio García Ruisuárez otorga un poder notarial, en el cual designa al procurador que le representaría ante el Consejo Real, en el litigio que entablaba sobre la materia:

Poder. En la Ziudad de Oviedo, a veinte y dos días del mes de mayo de mil septezientos y veinte y ocho ante mi el escribano y testigos Parezio el Dr. D. Benito Antonio Garcia Ruisuarez opositor a las cqathedras de ambos Derechos en su Universidad, y Dixo: que aviendo vacado la catthedra de prima de Leyes, y concurrido algunos opositores se les convoco para que acudiesen a la casa del Rector con sus títulos, y por ellos se les regularía las antigüedades y prezedenzias que cada uno huviesse de gozar en él modo de leer y escribir; Y aviendo llegado algunos y entre ellos el Dr. D. Benito Garcia este insinuo a dicho Rector mandasse exhibir los títulos a todos, y en su vista hiziese dichas regulaciones y se arreglasen a los Estatutos de la Universidad de Salamanca (mandados observar por los de esta y por S. M. nuevamente) (sic) en los que se prevenia que en las leciones de oposición y lecturas de Generales 
concurriendo Graduados de Doctor en Canones y leyes se devia dar preferencia y antigüedad a los Graduados en la Facultad de donse se leya (aunque fuesen menos antiguos y menores en Grado) (sic) y que siendo la catthedra que se leya de Leyes, los Graduados en ella de Doctor avian de preferir a los de Canones (aunque mas antiguos) porque el Grado de Canones para la Cathedra de Leyes no era de considerazion, ni habilitaba ni capazitava al opositor para que mediante el se pudiese oponer a catthedras de Leyes; y después entre los Graduados de Doctor en Canones regulasse por la misma razon por los Grados y antigüedad que cada uno tenia en la Facultad de Leyes (aunque menor) (sic) por deberse entender este en igual competencia y no el maior en Canones por no regir en la Facultad de Leyes: en cuia virtud prefirió a los Graduados de Leyes primero que a los de Canones (aunque mas antiguos) (sic) como fueron a los Doctores D. Zipriano Villaverde y D. Gabriel de la Villa en competencia del doctor D. Juan de solares graduado en Canones mas antiguo: $Y$ deviendo en virtud de dichos Estatutos y por la misma razon pasar a regular los Graduados de Doctores de Canones que faltavan por la antigüedad que cada uno tubiesse en la Facultad de Leyes; con pasión y por estar teñido de mucha amistad del Doctor D. Juan Francisco de Paz y su hermano Don Manuel Catthedraticos de Prima de Leyes y Canones y ser opositores dos sobrinos carnales de estos, y asimismo hallarse otros opositores todos de adentro del Claustro y Graduados de Doctores en Canones (por quienes espera dicho Rector la reeleçion en su oficio) (sic) ha menospreziado dichos Estatutos haciendo la regulazion por los Grados de Canones sin tener atención a los de Leyes (cuya Cathedra es la que devia predominar) (sic) posponiendo al otorgante (aunque mas antiguo en esta Facultad) (sic) a los parientes y otros de dichos Graduados y amigos de dicho Rector no teniendo/ respecto en ningunas determinaciones assi del Claustro como de Justicia a ningunos Estatutos sino la pasión que le regna; y para que se evite semejantes perjuicios assi al otorgante como a otros Dixo dava y dio todo su poder a D. Manuel Antonio Gutierrez vezino de la Corte de Madrid para que en su nombre ocurra ante S. M. y señores de su Consejo y saque Provision para que dicho Rector guarde cumpla en todo y por todo los Estatutos de dicha Universidad y de Salamanca (estando omisos aquellos) (sic) sin dexarle arbitrio ni interpretazion y principalmente para que entre los graduados de Doctor en Canones se 
prefieran los mas antiguos en la Facultad de Leyes (siendo la vacante de ella) (sic) y consiguientemente que siendo el otorgante mas antiguo que los Doctores D. Francisco y D. Joseph de Granda, y los Doctores D. Fernando y D. Joseph Quiros se le regule y prefiera a ellos por escederles en el Grado de la Facultad de Leyes en quatro años a unos y a otros en seis, y hallarse con el de Doctor en Canones, y que el poder que para ello se requiere assi se le da con todas conexidades y incidencias y con la clausula de sustituir en quien le pareziere; y se obliga a estar y pasar por lo que assi executare y a su cumplimiento obligo su persona y vienes y dio poder a las Justicias competentes se lo hagan cumplir siendo testigos D. Bernardo Vargas D. Alonso Vilandres y D. Francisco Tineo vecinos de esta Ziudad de quien el dicho otorgante a quien yo escribano doy fee conozco Dixo asi lo otorgava y otorgo y lo firmo = Dr. D. Benito Antonio Garcia Rusuarez = Ante mi Matheo Fernandez Andrade (Ibid., fol. s. n. rv. $)^{8}$.

Hecha la sustitución del poder, compareció en la Villa y Corte ante el Consejo regio Lucas de Miranda, a fin de lograr una real provisión favorable a su punto de vista (Ibid., dos fols. s. n. rv):

Muy Poderoso Señor. Lucas de Miranda en nombre del Dr. D. Benitto Antonio Garcia Rui Suarez opositor a las Catthedras de ambos Derechos de la Universidad de la Ciudad de Obiedo: $Y$ en virtud de su poder, que presento y juro: como mas haia lugar: Digo que habiendo vacado la Catedra de Prima de Leyes de dicha Universidad por jubilación del Dr. D. Mnauel de Paz su propietario que hizo de orden de V. A.: cocurrieron algunos opositores y se les comvocò a la Cassa del Retor, para que manifestasen sus títulos: y por ellos regular las antigüedades y precedencias que cada uno havia de gozar en el modo de leer o scrivir y entre ellos mi parte quien ynsistio a dicho Retor mandasse exivir los títulos a todos. $\mathrm{Y}$ en su vista hiziese dichas regulaciones y se arreglase a los Extatutos de la Universidad de Salamanca, mandados observar para dicha Ciudad de Oviedo, en los que se previene que en las lecciones de

8 "Sacose esta copia del original que ante mi passo y en mi oficio y poder queda a que en todo y por todo me refiero y en fee de ello yo el sobredicho Matheo Fernandez Andrade escribano de S. M. y del numero antiguo y perpetuo de esta dicha Ziudad su conzejo y xurisdiccion lo signo y firmo en ella en esta foja con la que va adjunta del sello terzero el dia mes y año de su otorgamiento $=$ En testimonio de verdad. Mattheo Fernandez Andrade". Signado y rubricado. 
oposición y lecturas de Generales concurriendo graduados de Dr. en Canones y leyes se devia dar preferencia a los graduados en la Facultad de donde se lehia (aunque fuesen menos antiguos y menores en grado) (sic). Y que siendo la Catthedra que se lehia de Leyes los graduados/ en ella de Docttor havia de preferir a los de Canones (aunque mas antiguos) (sic) porque el grado de Canones para la Catthedra de Leyes no hera de consideración ni avilittava al opositor para que mediante el se pudiesse oponer a Cathedras de Leyes; Y después entre los graduados de Doctor en Canones regulase por la misma razon por los grados y antigüedad que tenían en la Facultad de leyes (aunque menor) (sic) por deverse atender este en ygual competencia y no el maior en Canones por no regir en la Facultad de Leyes: en cuya virtud prefirió a los graduados de Leyes primero que a los de Canones aunque mas antiguos como fueron a los Docttores D. Zipriano Villaverde y D. Gabriel de Olavilla: en competencia del Dr. D. Juan de Solares graduado en Canones mas antiguo; Y deviendo en virtud de dichos Estatutos y por la misma razon pasar a regular los graduados de Docttores de Canones que falttavan por la antigüedad que cada uno tubiesse en la Facultad de Leyes, el dicho Retor llevado de passion y por ttener mucha amistad con el Dr. D. Juan Francisco de Paz, y su hermano D. Manuel Catthedraticos de Prima de Leyes y Canones, y ser opositores dos sobrinos de estos: Y asimismo por hallarsse otros opositores todos de dentro del Claustro y graduados de Doctores en Canones por quienes espera dicho Rector la reelecion en su oficio, a menospreciado dichos// Estatutos haciendo regulación por los grados de Canones sin tener atención a los de Leyes (y ser esta Cathedra la que devia predominar) (sic) posponiendo a mi parte aunque mas anttiguo en esta Facultad a los dichos parientes y otros de dichos graduados y amigos de dicho Rettor, no teniendo respeto en ningunas determinaciones asi de el Claustro como de Justicia a ningunos Estatutos sino la pasión referida: todo en perjuicio de mi parte como de otras personas y en contravención de dichos Estatutos, sobre que hizo el dicho mi parte las protextas y apelaciones que parecieron convenientes y consttan de los testimonios que presento y juro; y para remedio de lo rreferido $=$

A V. A. suplico se sirva de librar su Real Provission para que el referido Retor guarde y cumpla en todo y por ttodo los Estatutos de la Universidad de Salamanca sin darles ynterprettacion: $Y$ en su virtud entre los 
graduados de Dr. En Canones prefiera los mas antiguos en la Facultad de Leyes siendo la vacante de ella. Y por el consiguiente que por hallarse mi parte mas antiguo que los Docttores D. Francisco y D. Joseph de Granda: D. Francisco y D. Juan de Quiros, se le rregule y prefiera a ellos por exzederles en el grado de Leyes en quatro años a unos y a otros en seis y allarsse con el de Docttor en Canones: Ymponiendo para ello los apercibimientos/ comvenienttes. En Justticia que pido etc. Lucas de Miranda. Rubricado.

Enterado el Consejo de Castilla y con intervención de su secretario Lasalde, se reunió la Sala de Gobierno, integrada por su Ilustrísima ${ }^{9}$, como presidente, y vocales los señores Villacampa, Mercado, Cepeda, Orozco y Arriaza, quienes en la sesión celebrada en Madrid, el 9 de junio de 1728, acuerdan contestar al Dr. D. Benito Antonio García Ruysuarez, así como a la Universidad de Oviedo (Ibid., fol. s. n. v):

Despacho, para que el Rector guarde y cumpla en todo y por todo los Estatutos de la Unibersidad de Salamanca, sin darles ynterpretazion alguna, ni a esta parte justo mottibo de queja. Rubricado.

Cuando parecía ya concluida la controversia, la actuación del secretario universitario da origen a un nuevo incidente, del que su sustituto da fe, por contravenir la orden recibida y falsificar una parte de las actas universitarias relativas a este caso (Ibid., fols. s. n. rvr):

Yo Fernando Anttonio Suarez Nottario publico aposttolico por autoridad aposttolica y ordinaria vezino de estta Ziudad de Oviedo y sobsttittutto del Secretario de la Ynsigne Unibersidad de ella para en los pleittos y causas que a el se le mueven y el littiga, Zerttifico, Doy fee y verdadero ttestimonio a $\mathrm{S}$. M. Dios le guarde y señores de su rreal y supremo Consejo de Casttilla, y mas personas que el presente vieren, en como por mi testtimonio, y ante el Reptor de dicha Ynsigne Unibersidad, el Dr. D. Benitto Anttonio Garcia Rusuarez Abogado de los Reales Consejos y opositor a Cattedras de ambos Derechos en dicha Unibersidad, presento un pedimiento en que Dijo que antes de ahora havia ocurrido ante los señores de dicho Real y Supremo Consejo pidiendo se le librase Real Probision para que en las oposiciones a

9 Se trataba del arzobispo de Valencia, Andrés de Orbe y Larreátegui, que desempeñó el oficio desde 1727 hasta 1733. 
dichas cathedras y especialmente a la de Leies que se halla bacante se regulasen las anttiguedades por la dicha Facultad para leer a ellas, y que habiendo despachado nottificado y obedezido por dicho Rettor la referida Real Probision en su cumplimiento hizo dicha regulazion y por ella se havia pasado a leer a la rreferida Cathedra, y que deviendo el dicho secretario hazer el ttesttimonio general de ynpresion areglandose al auto de dicha regulazion y a la anttiguedad modo y forma que cada uno ttubo en leer, havia llegado a su noticia que faltando a estta legalidad y obligazion ttan propia de su ofizio havia hecho e ynprimido un ttesttimonio y discrizion de leziones y ttittulos contra dicha regulazion y forma con que se havia leído, poniendo las anttiguedades según su conttenplazion y de otros; y para que no se pudiese averiguar havia dado horden al impresor no los manifesttase a dicho Dr. D. Benitto; ocultando su cautela falsedad y pasion con querer recojerlos/ concluio en pedir que dicho Rettor mandase al referido secretario exsibiese y presenttase en la misma forma que se ynprimieron los referidos ttestimonios y que en su vista se ttrajese la rregulazion y ttesttimonio del modo que cada uno ttubo de leer, y que hallando no ser arreglado y conforme, se le castigase en las penas de pribazion y demás en que havia incurrido corporales y pecuniarias y en que a su propia costa se volviesen a ynprimir dichos ttesttimonios en la forma y manera que se havia leído y se hizieran dichas regulaciones mandando asimismo dar al dicho Dr. D. Benito el ttesttimonio necesario: Con cuia vista por el dicho Rettor se mando que el referido secretario zerttificase dentro de una ora de la regulazion anttiguedad y forma que se havia ttenido en leer y que presenttase los ttestimonios ynpresos; y nottificado dicho decretto en su obedecimiento en el dia veinte y ttres del presente en que fue dado, Zertifico haverse regulado por dicho Rettor en virtud de dicha Real Probision para leer a la referida Cathedra de prima de Leyes en la manera siguiente $=$ Primeramente que leiese el Bachiller D. Pedro Ruiz de Villar; después de estte el Dr. D. Joseph de quiros Baldes; después de estte el Dr. D. Fernando de Quiros Valdes; después de estte el Dr. D. Francisco de Granda Valdes; después de estte el dr. D. Joseph de Granda Valdes; después de estte el Dr. D. Benito Garcia Ruisuarez; después de estte el Dr. D. Juan Francisco Solares bustto; después de estte el Dr. D. Gabriel de la Villa Miranda = Y que no havia leído el Dr. D. Zipriano de Villaberde $=$ Aunque se havia opuestto a dicha Cathedra por haver consttado de Zerttificazion jurada de medico, hallarse enfermo. 
Y asimismo presentto ante su señoria dicho Repttor/ y a mi presencia veinte y ttres ttesttimonios impresos y sin firma alguna los que confesso haverse ynpreso de su horden y nottado. Y por ellos constto y resultto estar escriptto y regulado las anttiguedades en la forma siguiente $=\mathrm{el}$ Bachiller D. Pedro Ruiz del Villar, el Dr. D. Joseph Quiros; el Dr. D. Benitto Antonio Garcia Ruisuarez; el Dr. D. Francisco de Granda; el Dr. D. Fernando de Quiros; el Dr. D. Joseph de Granda Valdes, el Dr. D. Gabriel de la Villa, el Dr. D. Zipriano de Villaberde y el Dr. D. Juan de Solares $=\mathrm{Y}$ em vista de dicha regulazion y ttesttimonios ynpresos, por no estar areglados, por dicho Rettor por autto que probeio en dicho dia veinte y ttres del presentte se mando poner al dicho secretario preso en el Real Casttillo y forttaleza de estta dicha Ziudad que se le embargasen sus vienes y que se volviesen a ynprimir a su costa los referidos ttesttimonios conforme a la regulazion hecha por su Señoria de horden y mandatto de dichos Señores; y en ejecuzion de dicho autto se puso preso al dicho secretario. $\mathrm{Y}$ en el dia veinte y quattro sigientte e visto sueltto al susodicho y se halla sin haver pasado por mi ttesttimonio otra diligencia alguna. Y para que constte de pedimiento del dicho Dr. D. Benito Antonio Garcia Ruissuarez doy el presente que signo y firmo según resulta de dichos auttos que paran en mi poder y a que me refiero; en la Ziudad de Oviedo, a treinta de Jullio de mil settezienttos y veinte y ocho años. En ttestimonio de verdad. Fernando Antttonio Suarez notario apostolico. Signado y rubricado.

Resuelto el primer incidente, relativo al orden de intervención en la oposición convocada para la cátedra de Prima de Leyes; vacante en el Estudio ovetense, dada la irregularidad detectada en los testimonios impresos, que habían sido remitidos por el secretario titular de la Universidad, el procurador del afectado Dr. Benito Antonio García, compareció nuevamente ante el Consejo de Castilla, representando el nuevo incidente, en los siguientes términos:

Muy Poderoso Señor. Lucas de Miranda, en nombre del Dr. D. Benitto Anttonio Garcia Ruisuarez Abogado de los Reales Consexos y opositor a catthedras de hambos Derechos de la Unibersidad de la Ciudad de Obiedo ante V. A. parezco y Digo que habiendo ocurrido al vuestro Consejo, mi parte pretendiendo se diese vuestra carta y Provision para que en las oposiciones a cattedras, y especialmente a la de Leyes que se hallaba vacante, se regulasen las anttiguedades por la dicha Facultad para leer a ellas la que se mando despachar y despachò, y se nottifico al 
Recttor de dicha Unibersidad, quien la obedecio y en su cumplimiento hizo dicha regulación, y por ella se passo a leer a la rreferida catthedra, y deviendo el secretario de dicha Unibersidad hazer el ttestimonio General de ympresion, arreglándose a el auto de dicha rregulacion, y a la anttiguedad modo y forma que cada uno ttubo en leer, llegó a noticia de mi parte que faltando a esta legalidad y obligación, ttan propia de su oficio, havia echo/ e impreso un ttestimonio y discripcion de Lecciones y tittulos con una dicha regulación y forma con que se leyó poniendo las anttiguedades según su conttemplacion y de otros y para que no se pudiese averiguar dio horden al ympressor no los manifesttase a mi parte ocultando su cautela y falsedad con quererlos recojer por lo que mi parte ocurrio ante el Recttor haciendo expresión de lo referido y concluio pidiendo mandase al dicho Secrettario exsiviese y presenttase en la misma forma que se imprimieron los expressados ttestimonios y que en su vista se ttraxese la regulación y ttestimonio de el modo que cada uno ttubo de leer y que hallando no ser arreglado y conforme se le castigase en las penas de privación y demás en que havia incurrido corporales y pecuniarias y en que a su propia costa se volviesen a imprimir dichos ttestimonios en la forma y manera que se havia leydo y se hicieron dichas Regulaciones mandando dar a mi parte el ttestimonio necesario en cuya vista el Recttor mando al dicho Secretario Zerttificase dentro de una ora de la regulación anttiguedad y forma que se havia tenido en leer y que presenttase los ttestimonios impresos y nottificado, en su obedecimiento dio la zerttificacion de la regulación echa en virtud de la provision librada por los de el vuestro Consexo por el Rector para leer a la referida Cattedra de Leyes. Y// también presentò ante dicho Recttor veinte y tres ttestimonios impresos y sin firma alguna y por ellos consta y rresultta haver anttepuesto a mi parte quattro o cinco de los que leyeron. $\mathrm{Y}$ en vista de dicha regulación y ttestimonios impresos por no estar arreglados por dicho Recttor en el dia veinte y ttres de Jullio próximo pasado se mando poner y puso preso al dicho secretario en el Real Castillo y forttaleza de aquella Ziudad y que se le embargasen sus vienes y a su costa se imprimiesen los ttestimonios conforme a la regulación hecha por dicho Recttor, de orden y mandatto de los del vuestro Consejo, se le puso preso el dicho dia veinte y ttres, y el veinte y quattro se le bio sueltto al dicho secretario sin haver pasado a otra dilixencia alguna como consta del ttestimonio que presento y juro. Y respecto de que todos estos prozedimienttos prozeden de que el Recttor 
y dicho secretario de la Universidad y demás opositores son todos de aquella Ziudad, y mi parte de diez leguas de distancia, y ttienen pandilla, por lo qual y como no se castigan semejantes falsedades antepone dicho Secretario a su Arvittrio, faltando a la legalidad de su ministerio por ver que mi parte como es forasttero y de los mas antiguos, y el mas graduado que ay en aquella Unibersidad, en grave perxuicio de su punto y estimación, a lo que no se debe dar lugar, por tanto y para que (a) dicho Secretario y Recttor les sirva de escarmientto y a otros de exemplo./

A V. A. pido y suplico se sirva mandar se le de al secretario de aquella Unibersidad el castigo correspondiente a la falta de Legalidad con que hà prozedido y consta de el ttestimonio que llevo presentado y al rector por no haver prozedido en Justizia se le saque una buena multta para que sirva de escarmientto y no se executten semejantes delitos tomando las demás providencias condignas para que asi mi parte como otro qualquier forastero que se halle en aquella Unibersidad no se le haga semexante agravio contra su punto estimación litteracttura y graduación que además de ser Justicia recivira merced etc. Lucas de Miranda. Rubricado.

Enterada la Sala de Gobierno del Consejo de Castilla, a través de su secretario Lasalde, quien presentó el memorial de alegaciones formulado por el procurador del Dr. D. Benito Antonio García Ruysuárez, vecino de la ciudad de Oviedo, e integrada por el presidente, junto a los vocales “D. Pasqual de Villacampa, D. Marcos Salvador, D. Rodrigo de Zepeda, D. Juan Blasco de Orozco y D. Francisco de Arriaza", acuerda en Madrid, con data en el día 27 de agosto de 1728, amonestar al rector de la Universidad y; en cambio, impone una cuantiosa pena económica al secretario del Estudio:

Dese despacho para que el Rector de la Universidad de Obiedo, no permita, ni dè lugar a que el Secretario de ella, en las zertificaziones, ô testimonios que diere de las lecciones à cathedras, haga agravio a los opositores en la regulazion de títulos y antigüedades que les correspondieren. Y por la falta de legalidad con que dicho Secretario a prozedido, en regular la antigüedad, modo y formalidades que cada uno de los opositores tubo en leer a la Cathedra de Leyes de dicha Universidad, se le saquen seis ducados de vellón, aplicados a los pobres de la carzel de Obiedo. Rubricado. 
La Real provisión fue despachada el día 31 del mismo mes y año y el receptor de la Audiencia de Oviedo transmitió su cumplimiento con fecha del 15 de septiembre inmediato posterior:

Sevastian Lopez de Porto escribano de S. M. (Dios le guarde) (sic) y receptor de la Real Audienzia desta Ciudad y Prinzipado zertefico y doy fee, que por S. M. (Dios le guarde) (sic) y Señores de su Real y Supremo Consejo de Castilla y en los treinta y uno de Agosto pasado de este año se sirvieron despachar su Real despacho, autorizado de D. Joseph Gomez de Lasalde, su secretario de Camara cometido al Rector de la Unibersidad de esta Ciudad; y entre algunas cosas que por ella se manda es la de que Phelipe Antonio Suarez de la Vega Secretario actual de dicha Unibersidad por la falta de legalidad con que prozediera en regular la antigüedad modo y formalidades que cada uno de los opositores tuvieron en leher a la Cathedra de Leyes de dicha Unibersidad le sacasse seis ducados vellón aplicados a los pobres de la carzel de esta Ziudad de Oviedo y que de la ejecución y entrega de los dichos seis ducados a los referidos pobres remitiesse testimonio a dicho Real Consejo por mano de el señor Fiscal de el; con el qual e ssido requerido por/ parte de el Doctor don Benito Antonio Garcia Rui Suarez, Abbogado de los Reales Consejos y obpossitor a Cathedras de ambos Derechos en dicha Ynibersidad, y habiendo pasado a hazerle notorio a su merced D. Andres Marron Llano y Florez Canonigo en la Santa Yglesia Cathedral desta Ziudad y Rector actual de dicha Unibersidad, quien en su cumplimiento haviendola obedecido, mando se notificase a dicho Phelipe Antonio Suarez pusiese de manifiesto la dicha cantidad, $u$ en defecto se le embargasen sus vienes y después de algunas dilijenzias hechas en su cumplimiento, por dicho Phelipe Suarez se paso a poner de manifiesto dichos seis ducados em poder de su merced dicho señor D. Andres, quien en cumplimiento de dicho Real despacho de S. M. y con mi asistencia paso a las carzeles publicas de esta Ziudad y por su misma mano los repartio a los pobres que se allavan presos en ellas. Según que todo lo rreferido consta de dicho Real despacho dilijenzias y entrega de dicho dinero que se allan en su continuación y por ahora paran en mi poder para// entregar a la parte por quien fuy requerido y para que conste a S. M. y señores de dicho Real y Supremo Consejo y haverse cumplido con lo que se mandava, Doy el presente que signo y firmo en la Ciudad de Oviedo a quinze días del mes de septiembre de 
mil setezientos y veinte y ocho años. En testimonio de verdad: Sevastian Lopez de Porto. Signado y rubricado (Ibid., fol. s. n. v. $)^{10}$.

Puesto que había una pluralidad de opositores afectados con la representación elevada al Consejo Real por parte de Benito García; en razón del orden que debía guardarse en la actuación de las pruebas precisas para la provisión de la cátedra vacante, uno de ellos, José de Granda Valdés, aspirante a la misma, presentó un memorial ante el órgano político madrileño, argumentando en contra de la propuesta precedente de su coopositor:

En la ciudad de Oviedo a siete días del mes de Agosto de mil setezientos y veinti y ocho años ante mi escribano y testigos el Dr. D. Joseph de Granda Valdes Cathedratico de Sexto en la Universidad de esta Ciudad abogado y vezino de ella, dixo que aviendose puesto edictos a la substitucion de la jubilación de la cathedra de prima de Leyes que en dicha Universidad, como tal ajubilado goza y posee el Dr. D. Manuel Mauricio de Paz y Serrano, y opuestose a ella el obtorgante y otros, pareze a ser que por el Dr. D. Benito Garcia Ruisuarez se pretendio se alterasse y vulnerasse el estilo costumbre y orden, con que los Doctores y graduados debían de leer, y leyeron a otras cathedras que antecedentemente se vacaron sobre que presento diferentes peticiones ante el Señor Rector de dicha Universidad, y sobre que se hizieron diferentes autos que el referido Dr. D. Benito Garcia llevo por via de fuerza, por hazer tiempo para ocurrir como ocurrio ante su Magestad, Dios le guarde, y señores de su Real y Supremo Consejo de Castilla, y con siniestra relación, callando la observancia y costumbre, y la referida litispendencia gano real despacho, para que se leyesse conforme a la antigüedad del grado de Bachiller en Leyes, y en conformidad de los Estatutos de Salamanca, que además de no estar en uso en esta ni poder correr en ella, por ser promiscuas las cathedras de Canones y Leyes de ella, que no lo son las de Salamanca por no se oponer, como no se oponen los opositores de unas a otras./ Por lo qual y no querer alterar solo dicha costumbre y observancia en leer, sino también querer prevertir el estilo y orden de la regulación y antigüedad con que a cada uno se les debe poner y expresar en los testimonios que se imprimen y da el secretario de dicha

10 “Oviedo 15 de septiembre de 1728. Testimonio de haverse sacado al secretario de la Universidad la multa de seis ducados que le ympuso el Consejo". 
Universidad para remitir a Su Magestad y dichos Señores del Real y Supremo Consejo, lo que dio motivo, a que el obtorgante ocurriesse a quexarse ante dicho Señor y claustro, por petición que presento en el, pidiendo se observasse y guardasse el estilo y costumbre, que en semejantes casos siempre se avia observado y guardado sin cosa en contrario, cuios testimonios se mandaron remitir en la conformidad que estaban echos por dicho Secretario, por ir areglados a la costumbre y observancia que siempre a tenido dicha Universidad, como resulta del dado por dicho secretario al obtorgante en los treinta y uno de Julio próximo pasado de este año con mandato de dicho señor Rector y claustro, y a causa de que por dichos Dr. D. Benito Garcia Ruisuarez se pretenderá hazer alguna otra diligencia en prosecución de la que subreptiamente (sic) hizo antes de ahora en dicho Real y Supremo Consejo en la mejor forma que en derecho lugar aya, y mas firme sea, obtorga, que da todo su poder cumplido, y el que se requiere y es necesario a D. Ygnacio Antonio Manso del Bustillo residente en la villa de Madrid, para que en nombre del obtorgante y representando su propia persona ocurra ante su magestad y señores de su Real y Supremo Consejo de Castilla, y mas partes y tribunales donde convenga, y pueda hazer y haga contradicion, ô contradiciones a la pretensión, ô pretensiones intentadas, ô que pretenda intentar el dicho D. Benito Garcia Ruisuarez, y pueda pedir y pida el que se mande observar y guardar el estilo y costumbre, que siempre a tenido// y tiene esta dicha Universidad en semejantes casos que es en la forma y manera que contiene y se expresa en el citado testimonio de treinta y uno de Julio, y para ello gane el Real despacho ô despachos que sean nezesarios, y haga todas las diligencias judiciales y extrajudiciales que convengan y sean necesarias, que el poder que para ello se requiere, esse mismo le da y obtorga con todas las clausulas fuerzas y firmezas necesarias que da aquí por insertas y repetidas como si lo fueran a la letra, y con la de que le pueda substituir, obligación de persona y bienes, poderío de Justicias, y renunciación de todas leyes en general y en especial, asi lo obtorgo y firmo el obtorgante, a quien yo escribano doy fee conozco, siendo testigos D. Antonio Moran Valdes, D. Antonio Gonzalez Colloto, y Geronimo Moral vecinos de esta ciudad, y 
de la villa de Jijon $=$ Dr. D. Joseph de Granda Valdes $=$ Ante mi, Joseph de la Fuente ${ }^{11}$.

Al hacer uso de dicho poder, el citado apoderado otorgó, un mes más tarde, la sustitución, como representante, a favor de varios procuradores madrileños:

Sobstituzion. En la villa de Madrid a siete días del mes de septiembre año de mil settezientos y veinte y ocho, ante mi el escribano y ttestigos parezio D. Ygnazio Manso de Bultillo vecino de ella; y Dijo que usando de la facultad que en el poder anttezedentte a su favor otorgado, se le concede; le sobstituya y sobstituio en ttodo y por ttodo como en el se contiene; en Alonso de la Lama y Noriega, Juan Garzes, y Gabriel Pedrero, Procuradores de los Reales Consejos; y a cada uno yn solidum; y les relevo según es relevado; obligo los vienes en dicho poder obligados y ôttorgo sobstitucion en forma; y lo firmo a quien yo el escribano doy fee conozco, siendo testigos D. Francisco de la Lastra, D. Eugenio Porttales y Herranz, y D. Anttonio Sevilla residentes en estta Cortte $=$ Ygnacio Manso de Bustillo. Antte mi, Sevastian Garzia del Varco. Rubricados.

El fundamento de la contradicción formulada por el Dr. José Granda Valdés se encontraba en el certificado expedido por el entonces secretario del Estudio universitario ovetense, reproduciendo un memorial que presentó dicho catedrático para defender su punto de vista relativo a la antigüedad de los opositores, y por hacer la pequeña historia de unas oposiciones precedentes merece ser conocido en su integridad:

Yo Phelipe Antonio Suarez de la Vega notario publico apostólico y secretario de la Ynsigne Universidad Estudio General y Claustro de esta Ziudad de Oviedo y vezino de ella; Zerttifico doy fee y testimonio de verdad a S. M. Dios le guarde y señores del Real y Supremo Consejo de Castilla, en como en el claustro que se zelebro el dia veinte y quattro del corriente por el Recttor, Docttores y maestros de esta dicha Universidad que paso por testimonio de D. Juan Francisco Suarez Brabo notario

11 "Es copia del original que ante mi paso y en mi ofizio queda a que me refiero y en fee de ello yo el sobredicho Joseph de la Fuentte escribano de su Magestad del numero antiguo desta Ciudad de Oviedo su concejo y de las Reales rentas de ella y su partido lo signo y firmo el dia mes y año de su otorgamiento. En testimonio de verdad. Joseph de la Fuente". Signado y rubricado. 
apostólico mi sobstituto, entre diferentes cosas que se detterminaron en el, fue leyda y presentada la pettizion del thenor siguiente $=$

El Dr. D. Joseph de Granda Valdes Catthedrattico de Sexto vezino y Abogado de esta Ziudad ante V. S. en la mejor forma que haya lugar en derecho, parezco y Digo: que habiendo vacado la Catthedra de Ynstituta de esta Universidad por muerte del Dr. D. Francisco Fernandez Sabido me opuse ha ella y lo mismo los Docttores D. Enrique Fernando de Quiros Valdes, D. Francisco de Granda Valdes, y D. Benitto Garcia Ruysuarez, y siendo entonces solo Bachilleres, y sin embargo de ser yo y dichos D. Francisco y D. Benitto Garzia mas antiguos leymos después de dicho D. Fernando por este serlo en Canones por ganar antigüedad por dicho Grado de Bachiller en Leyes, aunque sea mas anttiguo como le ganan los Graduados de Bachilleres en Theologia, a los mas antiguos en el de Arttes, en conformidad de la costumbre usada y guardada en esta Universidad, y después haviendonos graduado todos de Doctores en la Facultad de Sagrados Canones, y vacado por muerte del Dr. D. Francisco Fernandez Sabido padre de dicho D. Francisco Sabido la Catthedra de Prima de Canones y opuestome a ella, yo y los referidos, y además los Docttores D. Juan de Solares, D. Zipriano Villaverde, y D. Gabriel de la Villa y D. Francisco de Paz, este por ser de Canones leyó el ultimo, y después el Dr. D. Juan de Solares, y después me toco a mi, a que no ley por hallarme enfermo para que presente zerttificazion del Dr. D. Joseph Dorado Medico de esta Ziudad y después de mi dicho D. Fernando de Quiros, y después dicho D. Franzisco de Granda, y después dicho D. Benitto, y después el Dr. D. Zipriano Villaberde, y después el Dr. D. Gabriel de la Villa sin embargo de estos dos ser Docttores mas antiguos por ser la Catthedra de Canones, en conformidad de la costumbre usada y guardada, y que siempre se huso y guardo en esta Universidad de leer assi, y en dicha forma como siendo la cathedra de leyes de leer los Graduados de Docttores en dicha Facultad los últimos aunque fuesen mas antiguos los Graduados de Doctores en Canones y/ haviendose dado dicha catthedra de Prima de Canones a dicho Dr. D. Francisco de Paz y las demás de resulta conforme a la Cattrhedra que cada uno tenia, por haver aszendido yo a la de Sexto, quedo baca la de Ynstituta que entonces rexenttaba, a que se obpusieron dichos Docttores D. Fernando de Quiros su propietario, D. Francisco de Granda y D. Benitto Garzia y otros y por ser este menos anttiguo en conformidad de 
dicha costumbre leyó primero que dicho D. Francisco este y después dicho D. Francisco y después dicho D. Fernando sin embargo de ser este menos anttiguo que los dos en el Grado de Bachiller de Leyes, y haviendose oy puesto edictos a la sobstituzion de la jubilazion de la Catthedra de Prima de Leyes nos opusimos todos los referidos a dicha Catthedra, menos dicho Dr. D. Francisco de Paz, Catthedratico de Prima de Canones, y por ser de la Facultad de Leyes dicha Catthedra, se hiço la regulazion en conformidad de dicha costumbre, mandando leer en primero lugar al Bachiller D. Pedro Ruyz, en segundo al Dr. D. Joseph de Granda y después a dicho D. Benitto, y después a dicho D. Francisco y después de esta a dicho D. Fernando y después a my y después a dicho D. Juan de Solares y después a dicho D. Gabriel y después a dicho D. Zipriano, sin embargo de ser mas anttiguo dicho D. Juan por ser estos dos Graduados de Doctor en leyes, de cuya regulazion llego a mi noticia havia apelado dicho D. Benito, por decir hera mas antiguo en el grado de Bachiller de Leyes y que por esso havia de leer después que dichos D. Fernando D. Francisco y yo, de que se le otorgo la apelazion al efecto devolutivo, y no al suspensivo, porque se quejo por fuerza ante los señores Rexente y oidores de la Real Audienzia de esta ciudad en que con dolo y malizia tubo dicho Pleitto haviendose remitido a ella, sin que a mi, ni los mas interesados se nos zitase como hera necesario, sin solicitar su vista, en grave perjuyzio mio, y del bien publico, cuyo fin se tubo para ajubilar dicho D. Manuel, y que los oyenttes y cursanttes en dicha catthedra tuviesen la enseñanza nezesaria, y en el ynterin, callando dicha observancia y costumbre dicho D. Benitto, como dicha Litis pendencia, con siniestra relación, gano Real Provision de los Señores del Real Consejo para que se leyese conforme al grado de Leyes, en conformidad de los Estatutos de Salamanca, que además de no estar en usso, ni obserbvanzia, lo referido, ni pueden correr en esta Universidad por ser promisquas las Catthedras de Canones y leyes de ella que no lo son las de Salamanca, por no se oponer los que se oponen a unas, a las otras, y en virtud de dicha Real Provision// sin darme parte a mi ni mas ynteresados, se mando contra dicha obserbanzia y costumbre leer después de mi a dicho D. Benitto Digo a este postrero que a mi, y a dicho D. Fernando y D. Francisco a que haviendosele notificado el auto de regulazion, este se aquieto, sin perjuicio de su derecho, y sin embargo de ser siniestra dicha relación leyó y dicho D. Fernando y yo mirando 
al bien publico de este Prinzipado, y que los estudiantes tuviesen la enseñanza publica que combenia, en conformidad del fin con que se hizo dicha jubilazion, y haviendose zerrado el concurso, y combocado por el bedel de esta Universidad para votarse dicha Catthedra, oy a las diez de la mañana, llegue a entender ayer a la ttarde que por el dicho D. Benitto se prettendia que el testimonio que el secretario de esta Universidad havia de remitir a los señores de dicho Real Consejo había de ser en la conformidad de dicha Real Provision, y como se havia leydo, siendo asi que por esta solos e manda leer, conforme a la anttiguedad del Grado, no que se me pribe, a mi, ni mas Graduados antiguos de los honores que como tales debemos de gozar, y que assi en el asientto, como en dichos testimonios siempre hemos gozado, y pareze que por haver dado dicho Secretario dichos testimonios conforme a dicha antigüedad, haviendose ansimesmo observado siempre, esa costumbre, pues en la vacante que hubo de la Catthedra de Prima de Canones sin embargo de haver leydo los últimos dichos D. Fernando D. Francisco y D. Benito, y yo fueron en ddichos testimonios los primeros dichos Doctores D. Zipriano y D. Gabriel, habiendo leydo primero y dando conforme al ultimo estado dichos testimonios, y en conformidad de dicha costumbre, dicho Secretario pareze que sin embargo de haver obrado asi conforme a su obligazion por dicho D. Benito se dio contra dicho Secretario querella por lo referido prendiéndole por ello, y mandando en mi perjuicio, que a su costa hiziese otros, y pusiese en dichos testimonios a dicho D. Benitto primero que a mi siendo yo graduado mas antiguo en Canones, y haverse observado en dicho ultimo estado la mesma orden como todo lo referido resulta de las vacantes de las cathedras que llebo referido de que pido testimonio de unas y otras, por lo qual y ser ziertto lo referido, a V. S. pido y suplico se sirva de mandar no se ygnobe de dichos testimonios, y mandando que en dicha conformidad, y en la en que se hallan impresos se remitan a dichos Señores tomando la Probidenzia que combenga para que en todo lo referido se guarden las/ costumbres que siempre se usaron y guardaron en esta Universidad para que en caso necesario, me opongo a dicho Auto en lo que me fuere perjudicial y esto debajo de la protesta de que no se rettarde la breve expedizion de dicha Catthedra, y que se de la enseñanza que combiene al publico, pues en utilidad de este zedo y consientto en mi perjuicio con la protesta de usar del derecho que me combenga por ser assi Justizia que pido 
costas juro lo necesario etc. y testimonio del auto y decretto que a esta pettizion se diere con su ynserzion: Dr. D. Joseph de Granda Valdes.

Y haviendose, oydo y entendido dicha pettizion por dicho Recttor y Claustro después de haverse tratado sobre lo referido mandaron que dichos Dr. D. Joseph de Granda Valdes y D. Benitto Garzia Ruysuarez diesen lugar ynterin el Claustro determinaba como lo executtaron; y de hecho acordaron uniformemente que sin perjuicio de la Real Probision que se hallaba obedezida por dicho Rector se remitiesen yn continente los testimonios que se hallaban echos em poder del Secretario por hallarse areglados a practica y libros de Grados y que las partes si tuviesen que pedir ocurriesen ante los señores del Real Consejo de Castilla y para ello se les diesen los testimonios que pedían y se les hiziese saber la determinazion del Claustro como se executto y remitieron dichos testimonios junto con los ynformes de la dicha Catthedra de Prima de Leyes como resulta de dicho Claustro.

Y habiendo rexistrado la vacantte que hubo de la Catthedra de Prima de Canones de esta Universidad el año pasado de settezientos y veinte y dos la de la Catthedra de Ynstituta del año de setezienttos y veinte y tres y otras vacantes mas anttiguas de todas ellas consta, haverse hecho los testimonios impresos generales conforme a la anttiguedad de los Grados Mayores y no conforme a la regulación de las FALTA las que se hallan en la forma que menciona el pedimento suso ynserto y en la misma siempre se ha observado y guardado en esta Universidad asta el presente como todo mejor consta de dichas vacantes sin que hubiese contra ella hecho contradizion, ni prezedido mandatto alguno.

Y asimismo consta de la vacante de dicha Catthedra que sin embargo de haverse dado traslado a los yntteresados de la prettension que ttenia dicho D. Benitto sobre la regulazion para leer, no dio lugar a que este se les notificase, presentando en un mismo dia otra pettizion suponiendo ser del dia anttezedente/ y apelando del anttezedentte de que asimismo se dio traslado de que insistiendo yn continente en dicha apelazion se le conzedio esta al efecto deboluttibo y denegó al suspensivo, en cuyo estado se quejo por fuerza sin que para uno y otro se hubiese zittado al dicho Dr. D. Joseph y mas interesados por no haver dado lugar a ello, en cuyo estado se remittieron los auttos a la Real Audienzia en donde 
estuvieron sin hazerse delixencia hasta que se gano la Real Probision por dicho D. Benito de que haze menzion dicha pettizion según lo uno y otro resulta de dicha vacantte acuerdo del Claustro y pettiziones en esta razon presentadas a que me refiero y en fee de ello y para que conste donde combenga doy el presente que signo y firmo de pedimientto del dicho Dr. D. Joseph de Granda Valdes en Oviedo y Jullio treinta y uno de mil settezientos y veinte y ocho años. En testimonio de verdad: Phelipe Antonio Suarez de la Vega. Signado y rubricado.

Amparado en este certificado y memorial elevado por el Dr. José de Granda Valdés, su procurador madrileño, nombrado a través de un poder notarial (AHPA. Sección protocolos. Año 1746, fol. 49rv.) ${ }^{12}$, elevó una petición al Consejo

12 Cf. AHPA. Sección protocolos. Escribano: José de la Fuente. Año 1746. Sign.7727, fol. 49rv: "Poder para pleito del Dr. D. Joseph de Granda Valdes. Año 1728. en la ciudad de Oviedo a siete dias del mes de Agosto de mil setecientos y veinte y ocho años ante mi escribano y testigos el Doctor Don Joseph de Granda Valdes Cathedratico de Sexto en la Universidad de esta ciudad abogado y vezino de ella y dixo que aviendose puesto edictos a la substitución de la ajubilacion de la cátedra de prima de Leyes que en dicha Universidad como tal ajubilado goza y posee el Doctor Don Manuel Mauricio de Paz y Serrano y opuestose a ella el obtorgante y otros pareza a ser que por el Doctor D. Benito Garcia Ruisuarez se pretendio se alterasse y vulnerasse el estilo costumbre y orden con que los doctores y graduados debian de leer y leyeron a otras cátedras que antecedentemente vacaron sobre que presento diferentes peticiones ante el señor Rector de dicha Universidad y sobre que se hizieron diferentes autos que el referido doctor D. Benito Garcia llevo por via de fuerza por hazer tiempo para ocurrir como ocurrio ante Su Majestad, Dios le guarde, y señores de su Real y supremo consejo de Castilla y con siniestra relacion callando la observancia y costumbre y la referida litispendencia gano Real despacho para que se leyesse conforme a la antigüedad del grado de Bachiller en Leyes y en conformidad de los estatutos de Salamanca que ademas de no estar en uso en esta ni poder correr en ella por ser promiscuas las cátedras de Canones y Leyes de ella, que no lo son las de Salamanca por no se oponer como nos e oponen los opositores de unas a otras por lo qual y no querer alterar solo dicha costumbre y observancia en leer sino tambien querer prevertir el estilo y orden de la regulación y antigüedad con que a cada uno se les debe poner y expresar en los testimonios que se imprimen y da el secretario de dicha Universidad para remitir a su Majestad, y dichos señores del Real y supremo Consexo lo que dio motivo a que el obtorgante ocurriesse a quexarse ante dicho señor y claustro por petición que presento en el pidiendo se observasse y guardasse el estilo y costumbre que en semejantes casos siempre/ se avia observado y guardado sin cosa en contrario, cuios testimonios se mandaron remitir en la conformidad que estaban echos por dicho Secretario por ir areglados a la costumbre y observancia que siempre a tenido dicha Universidad, como resulta del dado por dicho secretario al obtorgante en los treinta y uno de julio proximo pasado deste año con mandato de dicho señor Rector y claustro y a causa de que por dicho doctor D. Benito Garcia ruisuarez se pretendera hazer alguna otra diligencia en prosecución de la que subretitiamente hizo antes de ahora en dicho Real y supremo Consejo en la mejor forma que en derecho lugar aya y mas firme sea obtorga que da todo su poder cumplido y el que se requiere y es necesario a D. Ignacio Antonio Manso del Bustillo residente en la villa de Madrid para que en nombre del obtorgante y representando su propia persona ocurra ante su Magtestad y señores de su Real y supremo Consexo de Castilla y mas partes y tribunales donde 
de Castilla y reprodujo algunos de los aspectos más relevantes de su punto de vista en esta controversia, que contradecía abiertamente la representación inicial del Dr. Ruisuárez, conforme a la cual se había pronunciado anteriormente el órgano político madrileño:

Muy Poderoso Señor. Alonso de la Lama y Noriega en nombre y en virtud de poder que presento de el Dr. D. Joseph de Granda Valdes Cathedratico de Sexto de la Universidad de Obiedo: Ante V. A. como mas aya lugar en Derecho = Digo: Que aviendose puesto edictos a la substitucion de la Juvilazion de la Cathedra de Prima de Leyes, que en ella como tal jubilado goza el Dr. D. Manuel Mauricio de Paz y Serrano; y opuestose a ella asi mi parte como otros. Por el Dr. D. Benito Garcia Ruisuarez se pretendio alterar y vulnerar el estilo, costunvre y practica inconcussa, que siempre se ha observado en la forma y orden de leer los Doctores y Graduados a las Cathedrs, que antecedentemente han vacado en aquella Universidad para lo que presento diferentes pedimentos ante el Rector de ella, y se hicieron ciertos autos; de que por dicho Dr. D. Benito se quexo por via de fuerza en la Audiencia de aquel Reyno solo con el fin de ganar tiempo, y ocurrir, como lo hizo, al vuestro Consejo, en el que con siniestra relación, y ocultando la referida Litispendençia, y callando la mencionada practica, y costumbre, obtuvo Real Provission para que se leyesse conforme a la antigüedad del Grado de Bachiller en Leyes, y en conformidad de los Estatutos de Salamanca; lo que visto por mi parte y reconociendo que de lo referido, no solo se alteraba dicha costunvre y estilo en leer en perjuicio suyo, y de otros Doctores; sino que también se pervertia el orden de la regulazion de Antigüedad, con que a cada uno se le debía poner y expresar

\footnotetext{
convenga y pueyda hazer y haga contradicción o contradicciones a la pretensión o pretensiones intentadas o que pretenda intentar el dicho D. Benito Garcia ruisuarez y pueda pedir y pida el que se mande observar y guardar el estillo y costumbre, que siempre a tenido y tiene esta dicha Universidad en semejantes casos que es en la forma y manera que contiene y se expresa en el citado testimonio de treinta y unod e julio y para ello gane el Real despacho o despachos que sean necesarios y haga todas las diligencias judiciales y extrajudiciales que convengan y sean necesarias que el poder que para ello se requiere ese mismo le da y otorga con todas las clausulas fuerzas y firmezas necesarias que da aquí por insertas y repetidas como si lo fueran a la letra y con la de que le pueda sustituir obligación de persona y bienes poderio de justicias y renunciacion de todas leyes en general y en especial asi lo obtorgo y firmo el obtorgante a quien yo escribano doy fee conozco siendo testigos D. Antonio Moran Valdes D. Antonio Gonzalez Colloto y Geronimo Moral vecinos de esta ciudad y de la villa de Jijon. Dr. D. Joseph de Granda Valdes. Ante my, Joseph de la Fuentes". Rubricados.
} 
en los testimonios que da el secretario y se imprimen para remitirlos al vuestro Consejo: occurrio ante el Rector/ y Claustro de ella y con justificazion muy por menor de dicha practica y estilo, pidió no se alterasse dicha costumbre; y que se le diesse por testimonio, que es el que en devida forma presento $=$

Y mediante que de pervertirse el orden que siempre se ha observado en leer a todas las Cathedras que antecedentemente han vacado en aquella Universidad se siguen los perjuicios que se dexan considerar; mayormente no aviendose nunca observado en ella los Estatutos de la de Salamanca que no puedne correr en la de Obiwedo por ser promiscuas las Cathedras de Canones y Leyes de ella; que no lo son los de aquella, en que no se oponen los opositores de las unas a las otras: Por tanto, y para evitarlos $=$

Suplico a V. A. que aviendo por presentado dicho testimonio y sin envargo de dicha Real Provission librada a favor de dicho Doctor D. Benito Garcia Ruysuarez, se sirva de mandar se observe y guarde en dicha Universidad de Oviedo el estilo, practica y costumbre, que siempre ha avido en leer las Cathedras que en ella han vacado; y que en las vacantes que en adelante huviere no se altere, ni innove en manera alguna; dando para ello la providencia que sea de el agrado de V. A. y librando el Despacho necesario en Justicia que pido etc. Lizenciado D. Alexandro Joseph Garzòn. Alonso de la Lama y Noriega. Rubricados

La Sala de Gobierno del Consejo de Castilla acuerda, en un primer momento, con data del 10 de septiembre de 1728, que dicha petición e informe, con el certificado académico del secretario de la Universidad de Oviedo, remitidos por la parte del Dr. D. José de Granda, catedrático de Sexto, pasará al relator, quien era el licenciado Salazar, junto con los antecedentes, para examinar el fondo del asunto $^{13}$.

Un mes más tarde, reunida la citada Sala del supremo órgano colegiado del Reino, toma el acuerdo de acoger provisionalmente de modo favorable, y en

13 “El doctor Don Joseph de Granda Cathedratico de Sexto de la Unibersidad de Oviedo: Relator Lizenciado Salazar. Rubricado. Secretario Lasalde. Señores de Gobierno. Madrid septiembre diez del 1728. Juntese con los antecedentes, y al Relator". Rubricado. 
todos sus extremos, el planteamiento del Dr. José Granda Valdés, al mismo tiempo que solicita un informe personal del Rector de la Universidad:

Señores de Gobierno. Su Ilustrisima. Salvador. Zepeda. Orozco.

Sobre el contenido de este pedimiento ynforme la Unibersidad de Obiedo: Y por ahora y en el ynterin que por el Consejo otra cosa se manda y sin embargo de las provisiones despachadas a instancia del Dr. D. Benito Garcia Ruisuarez por decretos de nueve de Junio y veinte y siete de Agosto deste año se observen y guarden la costumbre y estilos de dicha Unibersidad. Madrid y octubre 14 de 1728. Licenciado Salazar. Rubricado

Ejecutando el acuerdo antecedente, se despacharon dos provisiones: una con data en el 25 de dicho mes y año, para solicitar el informe del Rector, mientras que la otra, en igual fecha, "para que por ahora se observe la costumbre" en las provisiones de las vacantes. Ambas Reales provisiones son extendidas en texto corregido por el secretario Lasalde ${ }^{14}$, y esta segunda es conocida en su tenor literal:

14 “D. Phelipe por la Gracia de Dios Rey de Castilla, de Leon, de Aragon, de las dos Sicilias, de Jerusalem, de Navarra, de Granada, de Toledo, de Valencia, de Galicia, de Mallorca, de Sevilla, de Cerdeña, de Cordova, de Corcega, de Murcia, de Jaen, señor de Vizcaya, y de Molina etc. $=\mathrm{A}$ vos el Recttor y claustro de la Universidd de la Ciudad de Obiedo salud y gracia. Saved que Alonsso de la Lama y Noriega en nombre del Dr. D. Joseph de Granda Valdes Cathedratico de Sexto de esa Universsidad nos hizo relación que habiéndose puesto edictos a la substitucion de la Jubilacion de la Cathedra de Prima/ de Leies que en ella como tal Jubilado gozava el Dr. D. Manuel Mauricio de Paz y Serrano, y opuestose a ella asi su parte como otros, por el Dr. Don Benitto Garcia Ruisuarez se havia pretendido alterar y vulnerar el estilo, costumbre y practica inconcusa que siempre se havia observado en la forma y orden de leer los Doctores y graduados a las cathedras que antecedentemente habían vacado en esa Universidad para lo que havia presentado diferentes pedimentos ante vos el Recttor de ella, y se habían hecho zierttos auttos de que por dicho Dr. D. Benitto se havia quexado por via de fuerza en la Audienzia// dese nuestro Reyno solo con el fin de ganar tiempo, y ocurrir como lo havia hecho al nuestro Consejo en el que con siniestra relación y ocultando la referida Litis pendencia, y callando la mencionada practica y costumbre, havia obtenido Real Provision para que se leyese conforme a la anttiguedad del Grado de Bachiller en Leies, y en conformidad de los Estatuttos de Salamanca. Lo que visto por su parte y reconociendo que de lo referido no solo se alteraba dicha costumbre, y estilo en leer en perxuicio suio y de otros Docttores, sino que también se perverttia el orden de la regulación de Anttiguedad, con/ que a cada uno se le devia poner y expresxar en los testimonios qie dava el secretario y se ymprimian para remitirlos al nuestro Consejo, havia ocurrido ante vos el Recttor y Claustro de ella y con justtificacion mui por menor de dicha practica y estilo; havia pedido no se alterase dicha costumbre, y que se le diese por testimonio que hera el que en devida forma presentada. $Y$ mediante que de pervertirse el orden que siempre se havia observado en leer a todas las Cathedras que antecedentemente habían vacado en esa Universidad se seguían los perxuicios que se dejavan considerar, maiormente no haviendose/ 


\title{
D. Phelipe por la gracia de Dios Rey de Castilla, de Leon, de Aragon, de las dos Sicilias, de Jerusalem, de Navarra, de Granada, de Toledo, de Valencia, de Galicia, de Mallorca, de Sevilla, de Cerdeña, de cordova, de corcega, de Murcia, de Jaen, señor de Vizcaia, y de Molina etc. =
}

\author{
A vos el Rector y Claustro de la Universidad de la Ciudad de Obiedo \\ salud y gracia.
}

\begin{abstract}
nunca observado en ella los Estattutos de la de Salamanca que no podían correr en la de Obiedo por ser promiscuas las Cathedras de Canones y Leies de ella, que no lo son los de aquella en que no se ôponen los opositores de las unas a las otras, por lo que Nos suplico que habiendo por presentado dicho testimonio y sin embargo de dicha nuestra Provision librada a favor de dicho Dr. D. Benitto Garcia Ruisuarez, nos sirviésemos de mandar se observase y guardase en dicha Universidad de Oviedo el estilo, practica, y costumbre que siempre abia habido en leer las Cathedras que en ella habían vacado; y que en las bacantes que en adelante hubiere, no se alterase ni ynovase en manera alguna dando para ello la providencia que fuese de nuestro agrado. Y// visto por los del nuestro Consejo con los antecedentes de esta dependiencia por autto que proveieron en catorce del corriente entre otras cosas se acordò dar esta nuestra Carta. Por la qual os mandamos que siendo con ella requerido ynformeis a los del nuestro Consejo por mano del ynfrascriptto nuestro escribano de Camara, de los que en el residen, lo que zerca y en razon de lo referido a pasado y passa para en su vista proveer lo que combenga. Que asi es nuestra voluntad. $\mathrm{Y}$ lo cumpliréis pena de la nuestra merced, y de treinta mil maravedís para la nuestra Camara, bajo de la qual mandamos a qualquier escribano que fuere requerido con esta nuestra Cartta, os la notifique/ y de ello de testimonio. Dada en Madrid a veinte y cinco de octubre de mil setecientos y veinte y ocho años = Siguen cinco firmas, con sus rúbricas, comenzando por el presidente del Consejo Real, Arzobispo de Valencia y concluye D. Francisco Osorio... Para que el Recttor y claustro de la Universidad de Oviedo, ynforme al Consejo sobre lo que se refiere como se manda". La notificación se produjo el 16 de noviembre de 1728, estando reunido el claustro de Rector, doctores y catedráticos en la Sala capitular de la Universidad de Oviedo, bajo la presidencia del licenciado D. Pedro de la Torre, Canónigo penitenciario de la Santa Iglesia Catedral de Oviedo, en calidad de rector, y con asistencia de los doctores: "D. Juan francisco de Paz, D. Juan Francisco Solarez, D. Zipriano de Villaverde, D. Gabriel de la Villa Miranda, el Reverendisimo padre maestro fray Estevan de la Torre, el Reverendisimo padre maestro fray Benito Feijo, D. Antonio Lopez Argüelles, D. Joseph de Granda Valdes, D. Fernando Quiros, D. Francisco Valdes,D. Manuel Rubin de Zelis, D. Ygnazio Menendez Valdes, D. Ramon de Junco y el Reverendisimo padre maestro fray Joseph Perez doctores y cathedraticos en dicha Universidad, estando asi juntos y habiendo prezedido recado de corttesia ley e hize saber dicho Real Despacho a los expresados señores que haviendole visto oído y entendido dicho señor Reptor le tomo en sus manos beso y puso sobre su pecho y corona, y dijo le obedece con el respecto y benerazion devida como a carta de su Rey y señor natural y para su cumplimiento pide al presente escribano le entregue una copia de dicho Real Despacho con ynserzion desta su respuesta y que en el yntirin protesta no le corra termino ni para perjuicio. Esto dijo respondio y firmo de que yo escribano doi fee = Lizenciado D. Pedro de la Torre. Ante my, Joseph de la Fuente. Rubricados. Doi fee como oy diez y ocho de Noviembre de mil setezientos y veinte y ocho entregue al señor Reptor la copia que pidió se le entregase por la deligencia de arriba. Fuente". Rubricado.
\end{abstract}


Saved que Alonso de la Lama y Noriega, en nombre Del Dr. D. Joseph de Granda Valdes Cathedrattico de Sextto de esa Universidad nos hizo relación que haviendose puesto edictos a la substituzion de la jubilacion de la Cathedra de prima/ de Leies que en ella como tal jubilado gozava el Dr. Don Manuel Maurizio de Paz y Serrano, y puestose a ella asi su parte como otros, por el Dr. D. Benitto Garcia Ruisuarez se havia pretendido alterar y bulnerar el estilo, costumbre y practica ynconcussa que siempre se havia observado en la forma y orden de leer los Doctores y graduados a las cathedras que antecedentemente habían vacado en esa Universidad, para lo que havia presentado diferentes pedimentos ante vos el Recttor de ella y se habían hecho ziertos Autos de que por dicho Dr. D. Benitto se havia quexado por via de fuerza en la// Audiencia de ese nuestro Reyno solo con el fin de ganar tiempo, y ocurrir como lo havia hecho al nuestro Consejo, en el que con siniestra relación y ocultando la referida litispendencia, y callando la mencionada practica y costumbre, havia obtenido Real Provision para que leyese conforme a la anttiguedad del Grado de Bachiller en leyes, y en conformidad de los Estatuttos de Salamanca. Lo que visto por su parte y reconociendo que de lo referido no solo se alteraba dicha costumbre y estilo en leer en perxuicio suio y de otros Doctores sino que también se pervertia el orden de la regulación de anttiguedad con/ que a cada uno se le devia poner y expresar en los testimonios que dava el secretario, y se ymprimian para remitirlos al nuestro Consejo, havia ocurrido ante vos el Recttor y claustro della, y con justificación muy por menor de dicha practica y estilo; havia pedido no se alterase dicha costumbre y que se le diese por testimonio, que hera el que en devida forma presentaba; $Y$ mediante que de pervertirse el orden que siempre se havia observado en leer a todas las Cathedrass que antecedentemente habían vacado en esa Universidad se seguían los perjuicios que se dejavan considerando// maiormente no haviendose nunca observado en ella los Estatuttos de la de Salamanca que no podían correr en la de Obiedo por ser promiscuas las Cathedras de Canones y Leyes de ella que no lo son los de aquella en que no se oponen los opositores de las unas a las otras, Por lo que nos suplico que habiendo por presentado dicho testimonio, y sin embargo de dicha nuestra Provision librada a favor de dicho Dr. D. Benitto Garcia Ruisuarez, nos sirviésemos de mandar se observase y guardase en dicha Universidad de Obiedo el estilo, practica y costumbre, que 
siempre havia habido en leer las Cathedras que en ella habían vacado y que en las bacanttes que en adelante hubiere no se alterase ni ynobase en manera alguna. Dando para ello la Providencia que fuese de nuestro agrado.//

Y visto por los del nuestro Consejo con los antecedentes de esta dependiencia por autto que proveieron en catorce del corriente entre otras cosas se Acordò dar esta nuestra carta.- Por la qual os mandamos que siendo con ella requerido sin embargo de las Provisiones despachadas por los del nuestro Consejo, a instancia de dicho Dr. D. Benitto Garcia Ruisuarez en virtud de Decrettos nuestros de nueve de Junio y veinte y siete de Agosto deste presente año, observeis y guardéis, y agais que se observe y guarde sobre lo que ba expresado la costumbre y estilos de esa Unibersidad, por ahora y en el ynterin que por los del Nuestro Consejo otra cosa se manda.

Que asi conviene a nuestro Real servicio, y lo cumpliréis pena de la nuestra merced, y de treinta mil maravedís para la nuestra Camara bajo de la qual mandamos a qualquiera/ escribano que fuere requerido con esta nuestra carta os la nottifique y de ello de testimonio. Dada en Madrid a veinte y cinco de Octubre de mil setecientos y veinte y ocho años $=\ldots$ Firman y rubrican los cinco miembros de la Sala de Gobierno: Andres ¿?? Portal de Cañas. De Zepeda. Francisco de Arn D. Francisco Ossorio. Yo D. Joseph Gomez de Lasalde secretario de Camara del Rey nuestro señor la hize escribir por su mandado, con Acuerdo de los de su Consejo. Registrada, Juan Alonso?? Romero. Por el Chanziller mayor, Juan Antonio??? Romero. Para que el Recttor y Claustro de la Universidad de la Ciudad de Obiedo cumpla y ejecute lo que se refiere como se manda. Secretario Lasalde. Gobierno. Corregida. Derechos diez y seis reales vellón.

Hasta mediados del mes de noviembre no se notificó esta Real provisión al claustro universitario, conforme al acta que se levantó por parte del Estudio ovetense:

En la Ziudad de Oviedo y Sala Capitular de la Ynsigne Unibersidad y Claustro general desta dicha Ciudad a diez y seis días del mes de Noviembre de mil setezientos y veinte y ocho años. Yo escribano requerido con el Real despacho desta otra parte estando celebrando claustro 
el señor D. Pedro de la Torre Canonigo Penitenziario en la Santa Yglesia Cathedral desta Ciudad y Retor desta dicha Unibersidad junto con los señores D. Juan Francisco de Paz Dr. D. Juan Francisco Solares, D. Zipriano de Villaverde Dr. D. Gabriel de la Villa Miranda el Reverendisimo padre Maestro fray Estevan de la Torre el Reverendisimo Padre Maestro fray Benito Feyjo Dr. D. Antonio Lopez Argüelles Dr. D. Joseph de Granda Valdes Dr. D. Fernando Quiros, Dr. D. Francisco de Granda Baldes Dr. D. manuel Rubin de Zelis Dr. D. Ygnazio Menendez Valdes Dr. D. Ramon de Junco y el Reverendisimo padre maestro fray Joseph Perez Doctores y Cathedraticos en esta dicha Unibersidad estando asi juntos y abiendo prezedido recado de cortesía ley e hize saber dicho Real despacho a los expresados señores que habiéndole visto oído y entendido dicho señor Reptor le tomo en sus manos beso y puso sobre su pecho y corona y dijo le obedece con el respecto debido como a carta de su Rey y señor natural y para su cumplimiento pide al presente escribano le entregue una copia de dicho Real Despacho con ynserzion desta su respuesta y que en el ynterin protesta no le corra termino ni pare perjuicio. Esto dijo respondio y firmo de que yo escribano doi fee = Lizenciado D. Pedro de la Torre. Antte mi, Joseph de la Fuente. Rubricados. Doy fee como oy diez y ocho del mes y año ariva dichos entregue al señor Rector la copia que pidió. Fuente. Rubricado. 
Enterados los claustrales de la Real provisión, con objeto de ilustrar al Consejo de Castilla de la veracidad del estilo, práctica y costumbre observada durante las precedentes décadas en las Aulas universitarias para la provisión de vacantes (AHPA. Sección protocolos. Año 1746, fol. 69rv) ${ }^{15}$, elevan un memorial, con los siguientes términos ${ }^{16}$ :

15 Con el mismo objeto, y para reforzar el recurso, el Dr. José Granda otorga un nuevo poder notarial: AHPA. Sección protocolos. Escribano: José de la Fuente. Año 1746. Sign.7727, fol. 69rv: "Poder para pleito. En la ziudad de Oviedo a veinte dias del mes de Noviembre de mill setecientos y veinte y ocho años ante mi escribano y testigos parecio presente el Dr. D. Joseph de Granda Valdes Cathedratico de Decreto en la Universidad de esta dicha ziudad Abogado y vezino de ella: y dijo que haviendose puesto edictos a la substitución de la jubilación de la cátedra de prima de Leyes que en dicha Universidad como tal ajubilado goza y posehe el Dr. D. Manuel Mauricio de Paz, y obpuestose a ella el otorgante y otros pareze a ser que el Dr. D. Benito Garzia Ruisuarez se pretendio se alterase y bulnerase el estilo costumbre y horden con los Doctores y graduados devian de leer, y leieron a otras catedras que antecedentemente vacaron sobre que presento diferentes peticiones ante el señor Rector de dicha Universidad, y sobre que se hizieron distintos autos, que el referido Doctor D. Venito Garzia llevo por via de fuerza por hazer tiempo para ocurrir como ocurrio ante s. M. (Dios le guarde), y señores de su Real y Supremo Consejo de Castilla, y con siniestra relacion callando la observancia y costumbre, y la rreferida litis pendenzia gano Real despacho para que se leiese conforme a la antigüedad de el grado de Bachiller en leyes, y en conformidad de los Estatutos de Salamanca, que ademas de no estar en uso en esta ni poder correr en ella, por ser promiscuas las cátedras de Canones y Leyes de ella que no lo son las de Salamanca, por no se oponer como no se oponen los opositores de unas a otras, Por lo qual y no querer alterar solo dicha costumbre, y observancia en ella, sino tambien querer pervertir el estilo y orden de la regulación y antigüedad con que a cada uno se les debe poner y espresar en los testimonios que se imprimen y da el secretario de dicha Universidad para remitir a S. M. y dichos señores de el Real y supremo Consejo, lo que dio motivo a que el otorgante ocurriese a quejarse ante dicho señor y claustro, por petición que presento en el, pidiendo se obserbase y guardase el estilo y costumbre que en semejantes casos siempres e havia observado y guardado, sin cosa en contrario, cuios testimonios se mandaron remitir en la conformidad que estaban echos por dicho secretario, por ir arreglados a la costumbre y observancia que3 siempre a tenido dicha Universidad, como resulta del dado por dicho Secretario al otorgante, en los treinta y uno de jullio proximo pasado de este año, con mandado de dicho señor Rector y Claustro, y a causa de que por dicho Dr. D. Benito Garzia Ruisuarez se pretendera hazer alguna otra delixenzia en prosecución de la que subrretiziamente, hizo antes de ahora en dicho Real/ y Supremo Consejo en la mejor forma que en derecho lugar aya y mas firme sea otorga que da todo su poder cumplido el que se requiere y es necesario a $\mathrm{D}$. Ignacio Antonio de el Bustillo residente en la villa de Madrid... pueda hazer y haga contradizion o contradiziones a la pretensión o pretensiones yntentadas o que pretenda yntentar el dichyo D. Benito Garzia Ruisuarez y pueda pedir y pida el que se mande obserbar y guardar el estilo y costumbre que siempre a tenido y tiene esta dicha Universidacd en semejantes casos, que es en la forma y manera que contiene y espresa en el zitado testimonio de treinta y uno de julio, y para ello gane el Real despacho o despachos que sean necesarios y haga todas las delixencias judiciales y extrajudiciales que convengan... siendo testigos D. Antonio Gonzalez Colloto, D. Luis de la Vega y Geronimo Moral vecinos y residentes en esta dicha Ciudad = Dr. D. Joseph de Granda Valdes. Ante my, Joseph de la Fuente. Rubricados.

16 "Oviedo, 20 de Noviembre de 1728. La Universidad. Ynforma como se le mando sobre la ynstanzia del Dr. D. Joseph de Granda Valdes". 
Muy Poderoso Señor. Haviendose hecho saber a el Claustro de esta Universidad, una Real Provision, despachada por V. A. a pedimiento del Dr. D. Joseph de Granda Valdes, en que se le hordena, y manda, ynforme a V. A. en rrazon de la prettension, yntroduzida en el Consejo por el Dr. D. Benitto Garzia Ruysuarez, zerca de la antigüedad, que ynttenta tener en la obposizion de las Cathedras por decir rezivio primero el Grado de Bachiller en la Faculttad de Leyes; lo que podemos poner en la Real Nottizia de V. A. es, que la Practica y Esttilo de estta Universidad siempre ha sido, que los que se hallan Graduados de Doctores en qualquiera de las dos Facultades, de Canones y Leyes, han preferido a los que estaban solo Graduados de Bachilleres aunque hubiesen rezivido el Grado de Bachiller antes que los Graduados de Docttores; y siendo la Catthedra vacantte de la Facultad de Leyes los graduados de Doctor en la misma Facultad/ prefieren a los Graduados en Canones, aunque sean mas antiguos y en la misma forma, siendo la Catthedra vacante en la Facultad de Canones el Graduado de Doctor en estta Faculttad, aunque sea mas moderno prefiere a los que están Graduados en la Facultad de Leyes, por lo qual, la prettension ynttroduzida por el dicho doctor D. Benitto Garzia Ruysuarez sobre que se le hubiese de conceder la anttiguedad por razon del Grado de Bachiller al dicho Dr. D. Joseph de Granda Valdes y a otros, que son mas antiguos en el Grado de Doctor es absoluttamentte contraria al estilo y practtica, que ttubo siempre estta Universidad en la obposizion de las Catthedras de ambas Facultades y ttambien la prettension, que ha ttenido sobre que se le diese la antigüedad, por razon de dicho Grado de Bachiller en los testimonios que se remittieron impresos por el Secrettario de esta Universidad; a V. A. ha sido contraria al estilo y practtica de ella, por quanto siempre se ha observado en dichos testimonios poner a los obposittores graduados conforme a la antigüedad de cada uno en el Grado de Doctor sin distinzion de Facultades.

Que es quantto hemos hallado en vista// de auttos de obposiziones de Catthedras y practica; y es de que podemos informar a V. A. de estte Claustro de la Universidad de Oviedo, Noviembre 20 de 1728. Lizenciado D. Pedro de la Torre, FALTA. Dr. D. Gabriel Antonio Villa Miranda. Cathedratico de Visperas de Canones. FALTA Cipriano de Billaverde, Cathedratico de Visperas de Leyes. Rubricados. Por Acuerdo del Claustro, Phelipe Anttonio Suarez de la Vega, secretario. Rubricado. 
Un mes más tarde del anterior memorial del claustro universitario ovetense, la sala de Gobierno del Consejo, reunida en Madrid, el 22 de diciembre de 1728, acuerda que pase "Al Relator con lo antecedente".

Ante el nuevo contenido de las provisiones regias, que concernían a este negocio, el secretario de la Universidad de Oviedo otorgó un poder notarial en Madrid, el 13 de abril de 1741, para comparecer ante el Supremo Consejo de Castilla, donde tenía un pleito pendiente, con algunos incidentes, instado por diversos miembros del Alma Mater asturiana, a fin de que su procurador compareciese en dicha sede judicial ${ }^{17}$.

En virtud de dicha representación, el nombrado para este oficio presentó un memorial ante dicho Tribunal, del siguiente tenor:

Muy Poderoso Señor. Geronimo Hernandez de Villalpando en nombre de D. Phelipe Antonio Suarez de la Vega, secretario de la Unibersidad de la ciudad de Obiedo, residente en esta Corte, ante V. A. parezco y Digo que a pedimiento del Dr. D. Benito Garcia Rui Suarez del Gremio y claustro de ella, en el año pasado de 1728, se libro Real Provision, por la que entre otras cosas se multo a mi parte en 6 ducados, con cierta aplicación, por haber supuesto que mi parte havia dado un testimonio sobre la Cathedra de Ynstituta de dicha Unibersidad, dando por mas antiguo al Dr. D. Joseph Granda Baldes, que al referido D. Benito, y posteriormente con instancia que hizo el citado D. Joseph Granda y ynforme que prezedio del Claustro, de la mencionada Unibersidad, se derogo la referida Providencia y declaro, haver sido dado dicho testimonio arreglado y según costumbre de aquella Unibersidad;

17 “Yo Pedro Garzia Oballe escribano del Rey nuestro señor residente en su Cortte y Probinzia doy fee que oy dia de la fecha, D. Phelipe Anttonio Suarez de la Vega, vezino de la Ziudad de Obiedo y Secrettario de la Unibersidad de dicha Ciudad, y residente al presente en estta Cortte; otorgo ante mi un poder, a favor de Geronimo Hernandez de Villalpando y Juan Casiano de la Reguera, Procuradores de los Reales Consejos, y en cada uno yn solidum, especial y generalmente para la defensa del pleito que tiene pendiente con la Unibersidad de la referida Ciudad de Obiedo, sobre diferentes capittulos que se le han puesto por los yndibiduos de la referida Unibersidad, cuyos auttos se hallan pendientes en el Real y Supremo Consejo de Castilla y para que en el puedan presentar y en todos los demás que se le ofrezcan con qualesquier personas y comunidades, pedimentos, demandas, papeles, testigos, y ynsttrumentos, hazer juramentos, recusaciones, zittaziones, prottextas, consentimientos, aparttamienttos, conclusiones, y lo demás que ocurra, con libre franca y general administración relebazion y obligazion de haverlo por firme en ttodo tiempo: Según constta de dicho Poder que original queda en mis rexistros de que doy fee, y a que me remitto y para que asi constte, donde combenga de pedimiento del referido D. Phelipe Antonio Suarez de la Vega, doy el presente que signo y firmo, en la Villa de Madrid a treze de Abril año de mil settezientos y quarentta y uno. En testimonio de verdad. Pedro Garcia de Ovalle". Signado y rubricado. 
y mediante combenir al derecho de mi parte hazer constar lo espresado en ciertos autos de Capitulos que se le an puesto que en ellos se incluye uno, en rrazon de este particular, callando la ultima resolución para que lo consiga $=$

Supplico a V. A. se sirva mandar que por el presente secretario escribano de Camara por cuio oficio paso el referido espediente se de a mi parte zertificacion de lo que ba espresado, que la quiere para el fin explicado/ que en ello recivira merced con Justicia que pido etc. Geronimo Hernandez de Villalpando. Rubricado.

Con un sólido apoyo en las Reales provisiones emanadas; la Sala de Gobierno del Consejo Real, integrada por los señores "Barcia, Henao, Quincoces, Bustamante, Guell y Guzman", acuerdaron, en la sesión celebrada en Madrid, el 12 de abril de 1741, con asistencia del secretario Lasalde: “Dese a esta parte Zertificacion de lo que constare, y fuere de dar, en razon de lo que expresa", lo que ejecuta el último citado al día siguiente, 13 de dicho mes y año:

En la villa de Madrid a 12 de Abrill de 1741 ante los señores del Consejo de s. M. se presento la petición que se sigue...

Y vista la petición antecedente por los dichos señores del Consejo por decreto que pronunciaron en el mismo dia 12 de este mes mandaron se diese a la parte de dicho D. Phelipe Antonio Suarez de la Vega zertificacion de lo que constase y fuese de dar en razon de lo expresado en cuio cumplimiento D. Joseph etc. Zertifico que ante los señores de el en 9 de Junio del año pasado de 1728 por parte del Dr. D. Benito Antonio Garcia Rui Suarez se presento una petición la qual es como se sigue...

Que vista la dicha petición por los señores del Consejo por Decreto que pronunciaron en el mismo dia 9 de Junio mandaron dar y se dio despacho en 14 de èl, para que el rector de dicha Unibersidad guardase y cumpliese en todo y por todo los Estatutos de la Universidad de Salamanca sin darles ynterpretazion alguna ni a dicho Dr. D. Benito Antonio Garcia Rui Suarez justo motivo de queja:

Despues de lo qual por parte de dicho Dr. D. Benito Antonio Garcia Ruisuarez se presento otra petición en el Consejo diciendo que habiendo... 
Que visto por dichos señores del Consejo por decreto que pronunciaron en 27 de Agosto del mismo año mandaron dar y se dio despacho en 31 de èl para que dicho Rector de la Unibersidad de Obiedo no permitiese ni diese lugar a que el secretario de ella, en las certificaciones ó testimonios que diese de las lecciones a Cathedras hiciese agravio a los opositores en la regulazion de títulos y antigüedades que les correspondieren.

Y por la falta de legalidad con que dicho Secretario havia procedido en regular la antigüedad modo y formalidades que cada uno de los opositores tubo en leer a la Cathedra de Leyes de dicha Universidad se le sacasen 6 ducados de vellón aplicados a los Pobres de la Carcel de Obiedo. $=$

Despues de lo qual por parte del Dr. D. Joseph Granda Valdes Cathedratico de Obiedo se presento ante dichos señores del Consejo en 10 de septiembre del mismo año una petición cuio tenor es el siguiente...

Que visto por dichos señores del Consejo pronunciaron el auto que se sigue.../

Y en consequencia del auto antecedente se dieron y libraron los despachos correspondientes en 25 del mismo mes. $\mathrm{Y}$ en su cumplimiento por dicha Universidad de Obiedo se hizo el ynforme que por dicho auto se manda. Y le remitio al Consejo, en cuio estado se alla dicho expediente al que me remito.

Y para que conste donde comvenga en virtud de lo mandado por los señores del Consejo doy esta certificación en Madrid etc.

De este modo se zanjó una controversia académica entre diversos candidatos a una vacante de la Facultad de Leyes, en la que se muestran claramente dos puntos de vista muy diferentes, con repercusión directa en el orden de actuación en los ejercicios exigidos para la propuesta final del claustro, antes de la resolución definitiva del Consejo de Castilla, con la Real provisión que incorporaba el nombramiento del elegido como nuevo titular de la cátedra.

Mientras el Dr. Benito Ruisuárez defendía un principio vigente en la Universidad de Salamanca, cuyos estatutos habían sido declarados aplicables como norma subsidiaria, en caso de ausencia de regla jurídica propia en la de Oviedo 
(Canella Secades,1873) ${ }^{18}$, de modo que si el concurso-oposición tenía lugar para aspirar a una cátedra de Leyes, se prefería y, por tanto, intervendría más tarde el bachiller legista más antiguo, aunque sus contrincantes tuvieran mayores grados en otras Facultades, y fueran anteriores en la obtención del bachilleramiento en Cánones, a diferencia de criterio sostenido por el Dr. José Granda sostenía, con el resto de colegas, al que se adhirió finalmente el órgano político español, al aplicar la peculiaridad del estilo practicado en el Estudio universitario ovetense, en el que no se diferenciaban los opositores en razón de la antigüedad del grado de bachiller, conforme a la especialización jurídica, Leyes o Cánones.

Un caso especial es el referido al secretario universitario, Felipe de la Vega (AHPA. Sección protocolos. Año 1746. Sign.7727, 33rv) ${ }^{19}$, ya que en principio

18 Así lo dispuso el título 11ํ de los Estatutos Viejos de 1609, al señalar: "en lo dudoso y omitido y que no estè declarado se guarde lo dispuesto por los estatutos de la Universidad de Salamanca, con que no sea ni se entienda en lo dispuesto por estos estatutos, o por nos después de ellos, o por los testamentarios que nos sucedieren en los dichos dos años que van declarados". Cf. Canella Secades, F. Historia de la Universidad de Oviedo y noticias de los establecimientos de enseñanza de su distrito, Oviedo 1873, p. 321, apéndice V.

19 Este secretario general de la Universidad tuvo diversos procesos ante el Consejo de Castilla, que en ocasiones fueron personales y privados, pero en otros, de mayor alcance, trataron sobre su responsabilidad académica, especialmente en 1744. Servirá como testimonio, entre los primeros, el que refiere el poder que insertamos a continuación: AHPA. Sección protocolos. Escribano: José de la Fuente. Año 1746. Sign.7727, fol. 33rv: “Poder para pleito. Año de 1728. En la ciudad de Oviedo a zinco dias de el mes de junio de mill setecientos y veinte y ocho años ante mi escribano y testigos pareció pressente D. Joseph Requejo Tineo, vezino y rexidor perpetuo de esta dicha Ciudad, y dijo que por quanto D. Phelipe Suarez vezino della y secretario de la Universidad de esta Ciudad, en una casa que esta llebando de foro de poco tiempo a esta parte, sita a la calle de el Rosal de esta Ciudad, a pretendido hazer y planttar como de hecho hizo y planto un nuevo cuarto y corredor de madera y antes de haverse perfizionado y sin dar lugar a ello y por el agravio que haze a la cassas en que vive el otorgante, que se halla ynmediata pribandole de la vista que desde sus ventanas tenia y tiene a toda la dicha calle de el Rosal; por el fuero que goza dicho D. Phelipe como tal secretario, ocurrio el otorgante ante el Rector de ella poniendo de embargo por el termino de la Ley a dicha nueba obra que se le admittio y se puso por fee su estado, y despues se hizo vista de oxos y otras diligencias por donde se justificaron y hizieron patentes y lexitimas las causas alegadas en dicha demanda de embargo, y deviendo de estimarlas y mandar y condenar al dicho D. Phelipe a demoler dicha nueba obra y que la pusiese en el punto y estado que antiguamente tenia dicha casa no lo a hecho dicho Rector, antes si a contemplación de dicho D. Phelipe a dado auto, concediéndole lizenzia de fabricar debajo de la fianza de demoler, de cuio autto como tan perjudicial el otorgante en tiempo y en forma ynterpuso apelación por ante su Majestad (Dios le guarde) y señores de su Real y Supremo Consejo de Castilla, y para mejorarla otorga que da todo su poder cumplido el que se requiere y es necesario a D. Juan Fuertes vezino de la villa de Madrid, para que en nombre de el otorgante y representando su propia persona, pueda ocurrir y ocurra ante s. M. y dichos señores, presentandose en el referido grado de apelación y pidiendo se le mande librar Real despacho pafra que dicho Rector y Notario ante quien pasa dicho pleito y autos los remita ante dicho Real Consejo, originalmente y assi remitidos y sobrez se revoque y anule el menzionado de licencia 
tenía plena noticia del pleito instado ante la Real audiencia del Principado de Asturias (Tuero Bertrand, 1979), creada en 1717, quien no duda en colocarse inicialmente al lado del recurrente Ruisuárez, pero ante las alegaciones del claustro y memoriales precedentes, debe expedir un certificado recogiendo la costumbre y estilo académico observado invariablemente en los concursos del Estudio universitario ovetense desde el siglo XVII.

Los dos protagonistas del incidente, ambos con domicilio en la capital del Principado de Asturias, no fueron inhumados en sus parroquias respectivas; sino que solicitaron su enterramiento en el convento de Santo Domingo de Vetusta, aunque en diferentes capillas (García Cuetos, 2001 y Taboada, 2002).

El doctor Ruisuárez estuvo casado con María Ignacia de la Fuente, y de su matrimonio dejó una hija, nominada Teresa, cuyo óbito precedió al de su generante, mientras que posteriormente tuvo otra descendiente, que le heredó, de nombre Vicenta María. El Dr. Benito Ruisuárez falleció, siendo catedrático de Vísperas de la Facultad de Leyes en la Universidad de Oviedo, el año 1746 y fue sepultado en la capilla de la Virgen del Rosario del templo dominicano ovetense, tal como refiere el acta levantada por el párroco de San Isidoro el Real (Archivo de la parroquia de San Isidoro. Oviedo. Libro 4 de defunciones, de 1741 a 1769, fols. 39v-40r.):

In marg. D. Benito Rui Suarez, no es de mi quenta.

En el dia veinte y ocho de marzo de mil setezientos quarenta y seis murió en la calle de Santo Domingo habiendo recibido los Santos sacramentos el doctor don Benito Rui Suarez Abogado que fue en esta ciudad. Testo ante Juan Antonio de la Vega escribano en esta dicha ciudad en cuio testamento dejo encargadas dos mil misas rezadas y elijida sepultura en la capilla de Nuestra Señora del Rosario de Santo Domingo. No dejo aniversario ni obra pia y en fee de ello lo firmo ${ }^{20}$. Juan Antonio Martinez. Rubricado.

y todo lo en su virtud fecho y obrado, pueda hazer y haga todas las delijenzias judiciales y estrajudiziales que conbengan y sean necesarias y las mismas que el otorgante haria y hazer podia presente siendo, que el poder que para todo ello se requiere y es necesario erse mismo le da y otorga con todas las clausulas fuerzas vinculos y firmezas para su validación necesarias que da aquí por ynsertas y repetidas como si lo fueran a la letra y con la de que le pueda sustituir... siendo testigos D. Joseph de Granda toro, D. Antonio Gonzalez Colloto y Geronimo Moral vecinos de esta dicha Ciudad. Joseph Requexo Tineo. Ante my, Joseph de la Fuente. Rubricados.

20 AHPA. Sección protocolos. Escribano: Juan Antonio de la Vega. Año 1746. Sign. 8147, fols. 1r-3r: “Testtamento y codizilio que otorgo el Dr. D. Venito Garcia Rusuarez y mas diligencias 
El Dr. José Granda Valdés falleció en 1767, y fue inhumado en la capilla de Santo Tomás del mismo cenobio dominicano ovetense (Libro 4 de defunciones, de 1741 a 1769 , fol. $47 v.)^{21}$ :

In marg. Doctor don Joseph de Granda. El diecisiete de noviembre (de 1767) fallecio mi feligres doctor don Joseph de Granda cathedratico de Leies en esta Universidad de Oviedo, no recibió los santos sacramentos por no dar lugar su repentina muerte y al dia siguiente a ella se enterro en la capilla de Santo Thomas del convento de Santo Domingo diçeseme se le encontró en papel simple una apuntazion de su letra y firma por donde consta la elecion de sepultura y otras varias disposiciones

echas sobre su apertura. Fol. 1r: Thestamento de el Dr. D. Benito Ruisuarez. Testamento de el Dr. D. Venito Garcia Rusuarez". Empieza con la diligencia de apertura y consta el cierre del testamento, en las casas de habitación del Dr. Venito Antonio Garcia Ruisuarez Catedratico de Visperas de Leyes de la Universidad de Oviedo", con las firmas de los testigos. Fols. 2r3r: "In Dei nomine amen. Sepan quantos esta vieren como yo el Dr. D. Benito Antonio Garcia Ruisuarez Abogado y Cathedratico de Visperas de Leyes estando enfermo y en mi sano juicio hago y ordeno este mi testamento y postrimera voluntad. Primeramente encomiendo mi anima a Jesucristo que la crio y redimio con su preziosa sangre y suplico a Maria Santisima su madre y mas santos y angeles de la corte celestial que por su intercesion y los demas de mi devocion la rezivan... y sea sepultado mi cuerpo en la iglesia de Santo Domingo y capilla de Nuestra Señora del Rosario a que le acompañen la comunidad de San Francisco y doze pobres y mando se den las mandas forzosas. Item digo estoy casado con doña Ygnacia de la Fuente quien no me trajo dote alguna.... mando se digan por mi alma dos mil misas, y se de de limosna a los pobres mil reales y a mi criado mando un vestido de los mios y para la criada un guardapies... dexo por mi unica heredera a mi hixa Teresa y mandola me encomiende a Dios y dexo a Josepha vezina de Lastres que fue mi criada doscientos reales. Item dexo por mis albaceas y testamentarios a D. Alexandro del Cantillo vezino de Lastres y a D. Joseph Villaverde y a cada uno in solidum con que revoco otro cualquiera que ubiere.... A doña Maria Ignacia de la Fuente mi mujer, por lo mucho que la quiero", le deja otras cantidades que le adeudaban, entre las cuales estaba el dinero que había devengado de su cátedra y no le habían pagado. Hecho en Oviedo, el 21 de enero de 1744. El codicilo, fol. 4r, está fechado en Oviedo a 21 de febrero de 1746, reconoce que no contempló en el testamento a su hija Vicenta Maria Garcia Ruisuárez, "la que no hera nacida quando hizo y otortgo dicho testamento", quiere y es su voluntad que dicha su hixa sea su usufructuaria unica heredera en todos sus vienes derechos y acziones muebles y raíces y por tutora y curadora de la dicha su hixa nombra a doña Ygnacia de la Fuente su legkitima muger y madre de dicha su hixa relevandola de toda fianza y por este su codicilo revoca anula y da por ninguno qualquiera otro testamento testamentos que antes deste aya escripto...". Firma y rubrica "Doctor D. Benito Antonio Garcia Rusuarez", junto con dos testigos presentes y el escribano.

21 Archivo de la parroquia de San Isidoro de Oviedo. Libro 4 de defunciones, fol.217v. Su hermano Francisco, también opositor a la vacante, tuvo su óbito algún tiempo después, inhumándose en el mismo convento de Santo Domingo de Oviedo: Archivo de la parroquia de San Isidoro. Oviedo. Libro 4 de defunciones, de 1741 a 1769, fol. 47v: "El 23 de diciembre de 1775 falleció el doctor D. Francisco de Granda Valdes célibe. Testó ante Francisco Javier Mere, secretario de la Universidad. Eligio sepultura en el convento de Santo Domingo". 
de que se me daría razon y por verdad lo firmo. Francisco Tamargo Argüelles. Rubricado.

Se ignora si ambos profesores de la Universidad de Oviedo, D. Benito y D. José, pertenecieron a la fraternidad laical de Santo Domingo de Guzmán, que probablemente los dominicos asturianos establecerían a través de su Tercera Orden, a partir de la erección conventual en 1518 (Canella \& Secades, 1888). No obstante, es indudable que los juristas citados compartían el espíritu de la misma, desde el testimonio de su fe, con la defensa de valores tan importantes como el servicio de la verdad, la defensa de la justicia y la vocación por el estudio.

Oviedo, 28 de enero de 2015

Festividad de Santo Tomás de Aquino

Nota: Las transcripiones de documentos antiguos se hacen respetando la ortografía y redacción original y las referencias deben conservar todos los datos de la ubicación del documento en el archivo histórico referido. La letra " $r$ " al final de la cita corresponde a "recto" y quiere decir, por delante del folio y la letra " $\mathrm{v}$ " corresponde a "vuelto", que significa por detrás del folio.

\section{Referencias}

AHN. Sección Consejos. Legajo 35238, exp. 9. Escribania de Cámara: Ayala.

AHPA. Sección protocolos. Escribano: José de la Fuente. Año 1746. Sign.7727, fol. 49rv.

AHPA. Sección protocolos. Escribano: José de la Fuente. Año 1746. Sign.7727, fol. 69rv.

AHPA. Sección protocolos. Escribano: José de la Fuente. Año 1746. Sign.7727, 33rv

Archivo de la parroquia de San Isidoro. Oviedo. Libro 4 de defunciones, de 1741 a 1769 , fols. $39 \mathrm{v}-40 \mathrm{r}$.

: Libro 4 de defunciones, de 1741 a 1769, fol. $47 \mathrm{v}$

Canella Secades, F. (1803). Historia de la Universidad de Oviedo y noticias de los establecimientos de enseñanza de su distrito, apéndice V. Oviedo, p. 321.

Canella Secades, F. (1903-1904). Historia de la Universidad de Oviedo y noticias de los establecimientos de enseñanza de su distrito (Asturias y León), 2ª ed., Oviedo. reimpr. 1985, p. 678; AA. VV.

Canella y Secades, F., (1888). Oviedo. Guía, Oviedo facs. 1984, pp 232-234. 
Episcopologio Civitatense (2010). Historia de los obispos de Ciudad Rodrigo (1168-2009), Salamanca: CEM, pp 323-326.

Esperabé de Arteaga, E. (1914). Historia pragmática e interna de la Universidad de Salamanca. Tomo primero. La Universidad de Salamanca y los Reyes, Salamanca; p 292.

García Cuetos, P. (2001). El convento dominico de Nuestra Señora del Rosario de Oviedo: historia y arquitectura. Oviedo: RIDEA.

. (2014). Querella contra el Dr. Tomás Serrano de Paz (Por el fiscal del obispo Caballero de Paredes CON el letrado del cabildo). Año 1656. Oviedo: RIDEA.

García Sánchez, J. (2012). El Doctor Tomás Serrano de paz (abogado y catedrático ovetense del siglo XVII). Oviedo: RIDEA.,

Taboada, J., (2002). Historia del convento de Nuestra Señora del Rosario de Oviedo: edición, estudio introductorio y traslación de Lázaro Sastre Varas, Salamanca-San Esteban. Oviedo: RIDEA.

Tuero Bertrand, F. (1979). La creación de la Real Audiencia de Asturias a principios del siglo XVIII, Oviedo. 